\title{
Developing enterprise collaboration: a methodology to implement and improve interoperability
}

\author{
Nicolas Daclin ${ }^{\mathrm{a} *}$, David Chen ${ }^{\mathrm{b}}$ and Bruno Vallespir ${ }^{\mathrm{b}}$ \\ ${ }^{a}$ LGI2P, Ecole des Mines d'Alès, parc scientifique G. Besse, Site de l'EMA, Nîmes cedex 130035 , \\ France; ${ }^{b} I M S$, University Bordeaux 1, 351, Cours de la liberation, Talence 33405, France
}

\begin{abstract}
The aim of this article is to present a methodology for guiding enterprises to implement and improve interoperability. This methodology is based on three components: a framework of interoperability which structures specific solutions of interoperability and is composed of abstraction levels, views and approaches dimensions; a method to measure interoperability including interoperability before (maturity) and during (operational performances) a partnership; and a structured approach defining the steps of the methodology, from the expression of an enterprise's needs to implementation of solutions. The relationship which consistently relates these components forms the methodology and enables developing interoperability in a step-by-step manner. Each component of the methodology and the way it operates is presented. The overall approach is illustrated in a case study example on the basis of a process between a given company and its dealers. Conclusions and future perspectives are given at the end of the article.
\end{abstract}

Keywords: enterprise interoperability; interoperability framework; interoperability measurement

\section{Introduction}

The changing industrial and economic context leads enterprises to develop impermanent partnership. As a consequence, the development of interoperability between partners has become a major issue for the last two decades, and this will remain true for the future. Furthermore, the development of interoperability in a short time and with minimum investment and effort is required. A first general definition of interoperability can be found in the Oxford dictionary (1999) where it is defined as 'the ability to interact in conjunction'. As the concept of interoperability is studied and developed in numerous fields (e.g. medicine, military, computer science...), it is further specifically defined with as many definitions as the number of fields that are dealing with this concept (IEEE 1990; (DoD 2001; ISO 2002a). In the frame of enterprise interoperability, several definitions also exist (Chen and Vernadat 2004). As an example, let us cite Vernadat (1996), who defines interoperability as 'the ability to communicate with another system and use the functionality of the other system'. More recently, the enterprise interoperability definition has evolved and has been clarified to become 'the ability of interaction between enterprise applications $^{1}$ at three enterprise levels: organisation (business model, decisional model and business process), application and data' (IDEAS 2003). Thus, enterprise interoperability has gained maturity over time, including today, in addition to technical aspects,

*Corresponding author. Email: nicolas.daclin@mines-ales.fr 
organisational aspects and information aspects (Wang and Xu 2012; Jardim-Goncalves et al. 2013; Panetto and Cecil 2013). From this point of view, when enterprises resolve to be interoperable, they have to consider fully these three interoperability aspects. Currently, enterprise interoperability is standardised and is defined as the 'ability of enterprises and entities within those enterprises to communicate and interact effectively' (ISO 2011) and numerous initiatives have been developed over the last years to define, analyse, measure and evaluate interoperability. For example, we can mention the main European initiatives with the Advanced Technologies for interoperability of Heterogeneous Enterprise Networks and their Applications (ATHENA) Integrated Project and Interoperability Research for Networked Enterprises Applications and Software (INTEROP) Network of Excellence or else the US initiative with the Command, Control, Communications, Computers, Intelligence, Surveillance and Reconnaissance (C4ISR) Architectures Working Group. Under FP7, the effort to develop interoperability was maintained with focus on interoperability utility service (COIN Integrated Project (COIN 2011)) and scientific foundation (Enterprise Interoperability Science Base, ENSEMBLE project (ENSEMBLE 2010)). On the one hand, these research works have effectively shown and validated that interoperability is not only a problem related to technological issues but also to conceptual and organisational issues. On the other hand, they have developed several solutions to facilitate and develop interoperability, according to the three previously-mentioned aspects. However, none of these works take an interest in or concentrate sufficiently on methodological aspects to guide, select and carry out their solutions within enterprises. In this respect, without a clear procedure to implement these solutions, their application still remains empiric, uncertain and potentially harmful for enterprises (e.g. loss of performance). This research work proposes to implement a methodology, involving several components and allowing enterprises to implement interoperability in a good condition, that is avoiding the use of hazardous approach, reducing time to develop interoperability and avoiding the implementation of non-adapted solutions. Precisely, this methodology is implemented through three main components: (1) a 'framework of interoperability', (2) a 'method to measure' interoperability and (3) a 'structured approach'.

The framework of interoperability structures and composes elements of available interoperability solutions and tools according to identified specific requirements and dimensions of interoperability to consider. It concerns the elaboration of a framework structuring and identifying aspects to consider through the selection of adapted interoperability solutions that meet enterprises' needs.

The method to measure interoperability allows the evaluation of the degree of interoperability between enterprises to define their strengths and weaknesses. It considers interoperability under two aspects such as interoperability before - which deals with the evaluation of maturity - and during - which deals with operational performances - the partnership.

The structured approach is a step-by-step procedure to guide enterprises during the interoperability solutions selection process, from the expression of their needs to the real implementation of solution.

Applying the proposed methodology in a company will help the company to detect possible interoperability problems with respect to its partners (suppliers, customers, subcontractors and so on). These interoperability problems are of different types and natures (ranging from the use of different syntaxes and semantics to represent information, incompatible IT services and infrastructures as well as different organisation structures and methods of works) that create obstacles to better mutually understand each other, to seemly communicate and transmit data and information and to establish collaborative processes. Based on the identified interoperability barriers/problems, the methodology 
will allow characterising the importance of the problems and then proposing appropriate solutions to solve the problems and improve the interoperability performances (such as interoperability cost, time and quality).

This article is structured as follows. After this introduction, research works within interoperability field are presented and discussed in Section 2. The set of methodology components (framework, interoperability measurement method and structured approach) and their relationships are outlined in Section 3. Section 4 discusses the three components developed in the methodology for interoperability. To illustrate and show how the methodology operates, a case study example is presented in Section 5. The final section presents the conclusion and the future perspectives for this research.

\section{Frameworks, models and methodologies for enterprise interoperability: a survey}

\subsection{Interoperability frameworks}

The term 'framework' refers to an organising mechanism to structure concepts or more generally 'things'. A framework is not an operational solution to solve a given problem. According to ISO (2002b), a framework is 'a structure expressed in diagrams, text and formal rules that relates the components of a conceptual entity to each other'.

Research on enterprise modelling and integration led to numerous frameworks (socalled 'modelling frameworks' within this domain) to ensure the consistency between different models and to clarify the position of the models and their limits of action. Although it is not dedicated to enterprise modelling, MERISE (Tardieu, Rochfeld, and Colletti 2000) represents, most probably, the first initiative. With three abstraction levels and two views, MERISE is a framework with six modelling areas. Afterwards, other frameworks, with different views and different levels, have been developed. However, the underlying concept remains the same. For instance, the enterprise modelling framework developed by the CIMOSA project (Computer Integrated Manufacturing Open System Architecture) includes three axes (ESPRIT Consortium AMICE 1993). The instantiation dimension allows to consider specific or partial architecture of enterprises. The derivation dimension is related to the life cycle of the system. The generation dimension defines the key views for the modelling (Vernadat 1996). Based on the same principles, the GIM framework (Chen and Doumeingts 1996) defines two axes such as (1) 'views' to consider different points of view coming from a systemic decomposition and (2) 'abstraction levels' based on a multi-layers approach, for the modelling of the system. Another example is the ZACHMAN framework (Zachman 2003) for the modelling of information systems. This framework is a matrix that considers the different aspects of enterprise (columns) and the views according to the types of actors of enterprise (rows).

Recently, several research initiatives on interoperability have proposed interoperability frameworks to structure issues and concerns in quite different ways.

The European Interoperability Framework (EIF) in the eGovernment domain (European Commission 2008) aims to provide a set of recommendations and specifications to connect the information systems of the public services. EIF defines three types of interoperability such as semantic, technical and organisational. This framework is developed in the field of interoperability for eGovernment services, but its concepts are generic and can be applied to the field of enterprise interoperability. Indeed, EIF considers interoperability according to three layers (semantic, technical and organisational) that indicate, implicitly, the main problems to solve to reach interoperability (conceptual problems, technical problems and organisational problems). A similar approach was 
also proposed in e-Health interoperability framework (NEHTA 2007), which identified three layers: organisational, informational and technical interpretabilities.

In the manufacturing field, the IDEAS interoperability framework (IDEAS 2003) defines three main layers - business (decisional model, business process and business model), knowledge, and ICT - with an additional vertical dimension (semantic). In this framework, the semantic issue is not considered as independent but as a problem which concerns all the levels where enterprises want to implement interoperability. This framework includes, as well, another aspect of interoperability: the knowledge. However, this layer is not considered by interoperability domain, as currently defined.

Later on, the ATHENA Interoperability Framework (AIF) proposed to structure interoperability issues and solutions at three levels: conceptual, technical and applicative (ATHENA 2003). Once more, this framework classifies interoperability according to its classical decomposition. The main goal of AIF is to capitalise interoperability solutions for each category; however, it is difficult to structure them accurately for an efficient exploitation.

Finally, the interoperability framework proposed by Chen and Daclin (2006), INTEROP (2006a) and (ISO 2011) allows the identification of available interoperability solutions according to a barrier-driven approach and takes into account the basic concepts addressed in existing frameworks such as interoperability barriers and enterprise levels. Interoperability barriers (also known as incompatibility) represent the problems that obstruct interoperability, that is conceptual barriers, technological barriers and organisational barriers. Enterprise levels represent all levels in enterprise where interoperability can be implemented, that is data, services, process and business. More recently, in a European FP6 project to develop a science base for enterprise interoperability, a broader framework extends the interoperability dimensions to non-technical aspects (Charalabidis, Jardim-Gonçalves, and Popplewell 2010; Ducq, Chen, and Doumeingts 2012). In Naudet et al. (2010), concepts of interoperability framework have been formalised in terms of an ontology with further addition of system theory concepts.

The greater part of these frameworks structures interoperability according to the conceptual, organisational and technology categories. ${ }^{2}$ This decomposition is consistent with the problems of interoperability that are identified and also with the abstraction levels defined in modelling frameworks such as GIM (Chen et al. 1996) or MERISE (Tardieu, Rochfeld, and Colletti 2000). However, the majority of these frameworks include only this dimension of problems and does not allow existing interoperability solutions to be structured and capitalised in a precise way. To get an efficient exploitation of an interoperability framework - that means to select interoperability solutions adapted to enterprises' needs - it is necessary to consider other dimensions. For instance, both IDEAS and ATHENA, specifically developed for interoperability, do not consider a dimension of 'views', that is a dimension that considers different levels where interoperability takes place in enterprise. This dimension has to be considered to structure interoperability problems accurately and to target precisely interoperability solutions. Furthermore, none of these frameworks includes approaches to develop interoperability (integration, unification and federation) as mentioned by ISO (1999). Once more, the consideration of this aspect allows to better structure and target solutions for enterprises. Table 1 provides a comparative overview of the research works about framework for interoperability. It shows the five main characteristics to consider for the development of the framework of interoperability and includes (1) the consideration of the needs in terms of interoperability, (2) enterprise's views to be taken into account, (3) the categories of interoperability, (4) the approaches to develop interoperability and, finally, (5) the capitalisation of interoperability solutions. 
Table 1. Comparative study of the different interoperability frameworks. ${ }^{1}$

\begin{tabular}{lccccc}
\hline & Needs & Views & Categories & Approaches & Solutions \\
\hline EIF & + & - & +++ & - & ++ \\
IDEAS & + & ++ & +++ & - & - \\
AIF & + & - & ++ & - & ++ \\
INTEROP & + & +++ & +++ & +++ & +++ \\
\hline
\end{tabular}

Note: ${ }^{1}$ We adopt the following notation to evaluate existing research works:

- +++: best address the issue

- ++: partly address the issue

- +: relevant to the issue

- -: irrelevant to the issue.

\subsection{Models to measure interoperability}

The fact that interoperability can be improved means that metrics for measuring the degree of interoperability exist. Measuring interoperability allows a company knowing its strengths and weaknesses to interoperate with a third company and to prioritise actions to improve their partnership ability.

Existing approaches to measure interoperability are mainly focused on maturity measures (C4ISR Architecture Working Group (AWG) 1998; Kasunic and Anderson 2004; Guo, Wang, and Liao 2011; Van Staden and Mbale 2012; Camposa et al. 2013; Guédria, Naudet, and Chen 2013). The term 'maturity' has different meanings in different domains. The most literal definition is just 'how much you act like an adult'. In psychology, maturity is the ability to respond to the environment in an appropriate manner. In the interoperability domain, maturity refers to the ability of a system or entity to adapt and make necessary changes to exchange information/service and use the information/service exchanged. A maturity model (whatever its application domain) includes levels consisting of a predefined set of interest areas. These levels are measured by the achievement of the specific and generic goals that apply to each predefined set of interest areas. Furthermore, a maturity model provides recommendations and practices to evolve throughout maturity levels for continuous improvement and the achievement of full maturity regarding the interest areas (adapted from CMMI). The term 'maturity model' was popularised by the SEI (Software Engineering Institute) when it developed the Capability Maturity Model (CMM) in 1986. Five maturity levels were proposed (CMM 2004), namely initial, repeatable, defined, managed and optimising. Several other models have been developed in different disciplines, focusing on different levels of the enterprise, for example the Service-Oriented Architecture Maturity Model (Bachman 2005), the Extended Enterprise Architecture Maturity Model (IFEAD 2004) and the NASCIO (NASCIO 2003) Enterprise Architecture Maturity Model. These models aim at evaluating processes within organisations (business processes) and identifying best practices useful in helping them to increase the maturity of their processes and then their level of performance.

Regarding interoperability issues, the models presented below define maturity levels regarding interoperability. Some models focus on the evaluation of maturity between several systems and others focus on the evaluation of maturity of a single system. Furthermore, some models give recommendations to evolve through maturity levels to reach full interoperability. The LISI (Levels of Information Systems Interoperability) is one of the first initiatives and proposes a maturity model for measuring interoperability in five levels: isolated, connected, functional, domain, enterprise (C4ISR Architecture 
Working Group (AWG) 1998). This model allows definition, measurement and assessment of the interoperability of information systems. Moreover, LISI goes further and takes into consideration other factors, which affect the ability of information systems to interoperate. These factors are categorised into four attributes known as procedures, applications, infrastructures and data.

Several similar approaches have been developed based on LISI and considering other aspects of interoperability. The OIM (Organisational Interoperability Model) (Fewell and Clark 2003) is an extension of the LISI and addresses the evaluation of the interoperability maturity from an organisational point of view and according to five levels. The goal of the OIM is to extend the LISI models to other fields of application. This is possible by considering the organisational aspect. Furthermore, their levels are aligned for an efficient integration of these models, as presented by Morris et al. (2004).

The LCIM (Levels of Conceptual Interoperability Model) (Tolk, Diallo, and Turnitsa 2007) considers the evaluation of the conceptual interoperability and defines seven levels to evaluate this aspect. The LCIM has been initiated according to the assumption that interoperability is not only a technical problem but also a conceptual problem. Thus, this model focuses on the quality of data - in terms of documentation - to exchange between interoperable systems. To reach a high level of maturity in terms of conceptual aspect, LCIM recommends the adoption and the use of standards.

Based on these existing maturity models, the ATHENA project has developed - for manufacturing enterprises - the EIMM (Enterprise Interoperability Maturity Model) to address interoperability issues at all levels of the company (ATHENA 2005a). Defining the EIMM involves two tasks: (i) identifying the main areas of concern on which an enterprise needs to work to achieve interoperability both internally and externally; (ii) defining the maturity levels that describe the improvement path for each area of concern. The EIMM is applied in an intra-enterprise context, that is before collaboration, and attempts to cover all fields of industrial systems that are related to interoperability. However, it does not consider the classical categorisation of interoperability (conceptual, technological and organisational).

From an operational performance measurement point of view, we can mention contributions such as Kasunic and Anderson (2004), Ford (2008) and Hamilton, Rosen, and Summers (2002), which have developed metrics for interoperability measurement.

Kasunic has developed some metrics (namely quality attributes) to evaluate interoperability, mainly in terms of communication of information. In this sense, he has developed several equations (connectivity, capacity, overload, underutilisation, undercapacity) to evaluate operational interoperability (e.g. overload metric to measure if more data, than a system is able to transmit, have to be exchanged). Ford has developed several modes of interoperability aiming to offer operational effectiveness. Thus, seven modes and their associated metrics exist (directional, auto, pure, contextual, time-variant, constrained upper bound, collaborative/confrontational). For instance, we can mention directional mode that considers either bi-directional (partner $1 \longleftrightarrow$ partner 2) or unidirectional (partner $1 \rightarrow$ partner 2) interoperability. Hamilton, as for him, proposes a method based on operational requirements definition (e.g. operational readiness, speed exchange) and evaluates if systems meet interoperability requirements. He also proposes a table to evaluate the level (colour code) of satisfaction of interoperability requirements. Finally, other works that can be related to interoperability measurement exist. In this way, we can mention the Service Level Agreement (Verma 1999) that takes an interest in the measure of the quality of services between a provider and a customer. In Yahia, Aubry, and Panetto (2012), some formal measures for semantic interoperability have also been proposed. 
Table 2. Comparative study of the different models to measure interoperability.

\begin{tabular}{lcccc}
\hline & & & & Operational \\
& Categories & Maturity (intra-) & Maturity (inter-) & \begin{tabular}{c} 
performances \\
\hline LISI
\end{tabular} \\
OIM & ++ & - & ++ & - \\
LCIM & ++ & - & +++ & - \\
EIMM & ++ & - & +++ & - \\
Operational effectiveness (Ford 2008) & - & ++ & - & - \\
(Kasunic et al. 2004) & - & - & - & +++ \\
\hline
\end{tabular}

Some of maturity models presented above consider the classical categorisation of interoperability, that is conceptual, technological and organisational. However, there is no general model that allows all the categories to be gathered and evaluated. Furthermore, these models focus on the evaluation of the maturity and do not consider the operational aspect of interoperability. Therefore, it is difficult to measure and to evaluate the performances related to the exchange and the compatibility. In the frame of the development of the methodology, it is required to propose tools to measure interoperability during interoperations. Table 2 provides a comparative overview of the research works about interoperability measurement. It shows the four main characteristics to consider for the development of the method to measure interoperability and includes (1) the categories of interoperability, (2) the intra-enterprise maturity evaluation, (3) the inter-enterprise maturity evaluation and (4) the operational performances in terms of interoperability.

\subsection{Methodologies to develop enterprise interoperability}

The term 'methodology' refers to a set of methods, models and approaches to solve a complex problem. Enterprise Interoperability is, in fact, a complex problem that impacts not only the technical aspect, but also economic and human aspects. In this case, the use of methodology is required to solve interoperability problems.

Most of the enterprise engineering methodologies developed up to now are based on enterprise modelling techniques to analyse and to design a system. Some of them, such as Structured Analysis and Design Technique (Marca and Mcgowan 2005) or integrated computer-aided manufacturing (Menzel and Mayer 1998), highlight the use of graphical formalisms and structured approach to build and validate the developed model. Other methodologies focus on a specific aspect of the system to design and analyse. For instance, the GRAI methodology (Chen and Doumeingts 1996; Doumeingts, Vallespir, and Chen 1998) takes an interest in the modelling of the decisions made in an enterprise. This methodology uses graphical languages and a participative and structured approach. Other methodologies, such as CIMOSA (ESPRIT Consortium AMICE 1993), allow to perform enterprise integration by the modelling of their industrial processes.

Recently, methodologies have been developed to implement interoperability between partners (Campos et al. 2008). For instance, the Model Driven Interoperability (MDI) (Bourey et al. 2007) - based on the Model Driven Architecture (MDA) (OMG 2003) allows the generation of interoperable enterprise applications, from enterprise models that are successively transformed through different levels. The MDI follows the structure of the MDA from the computation-independent model (CIM) to the platform-specific model (PSM) via the platform-independent model (PIM) (Figure 1). 


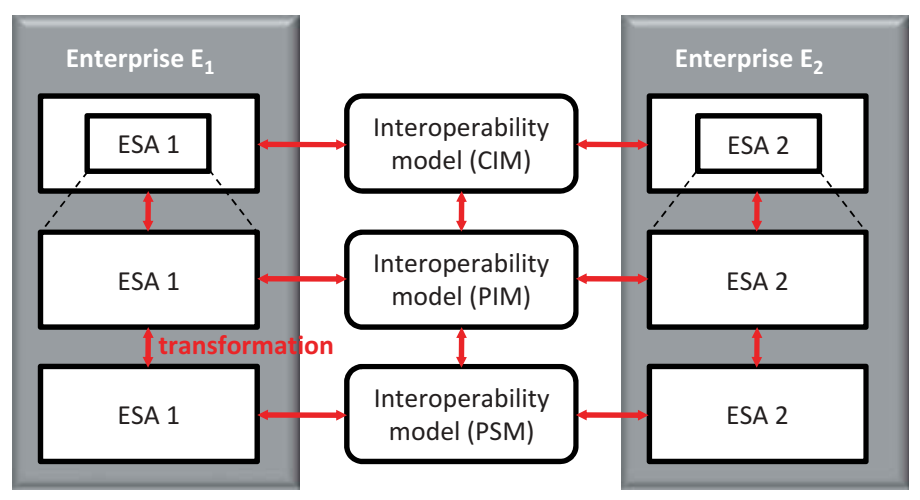

Figure 1. The reference model for MDI.

Note: ESA stands for Enterprise Software Application.

Instead of starting to tackle the interoperability problem from the code level, MDI advises to start from enterprise and business models and to transform them successively, until reaching interoperable Enterprise Software Applications (ESA). Thus, the computation independent model allows to collect the system's needs thanks to enterprise modelling tools. At this stage, the system requirements, within the environment in which the system gets ready to operate, are represented. This level is related to the description of business models and business requirements for the software system. The platform-independent model ensures to fulfil the functionalities defined at the upper level. To that purpose, system functionalities are modelled but without defining how and in which platform they will be implemented. The PSM transforms the model of the PIM level to obtain interoperable enterprise software applications that satisfies the needs expressed at the CIM level. Precisely, PSM level describes the realisation of software system according to the selected platform and it fully focuses on technological point of view. Finally, as far as transformations are concerned, MDI takes into consideration the model's transformation both vertical and horizontal. Vertical transformations are performed following a complete MDA approach. Horizontal transformations ensure the interoperability of enterprise at different level of abstraction (enterprise models) by means of model transformations. It is notable that MDI focuses on the technology problems of interoperability and does not consider the conceptual and organisational aspects.

The Business Centric Methodology for Enterprise Agility and Interoperability (OASIS 2006) allows the development of enterprises' interoperability regarding information technology. The main challenge of the BCM is to reduce business costs by making e-business easier, to improve the time to market of solution of collaboration and to reduce the cost of collaboration between partners. The BCM considers that interoperability is possible if and only if conceptual, business, extension and implementation layers are aligned as shown in Figure 2. The conceptual layer has to improve the semantic by the alignment of terminologies and allows the real meaning of the business vocabulary used in a given enterprise to be known. The expected result is the use of terms having the same meaning for all enterprises which will collaborate. The business layer has to ensure the understanding of the objectives - by partners - allocated to the collaboration. This is done by the construction of process models. These process models are based on the objectives and have to include information to exchange. At this stage, a target model is defined. The extension layer ensures the projection of the target model into a 'community of interests' database, 


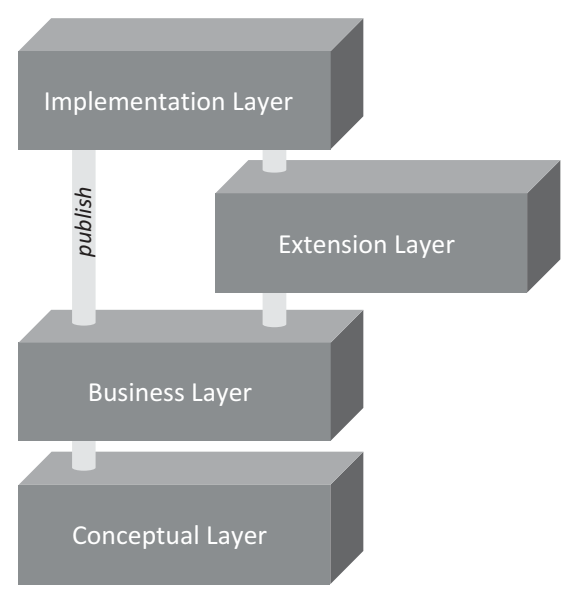

Figure 2. The four layers to achieve interoperability in BCM.

according to the needs of collaboration of the enterprise. This layer allows the finding and selection of a partner, which will allow to satisfy the objectives of the enterprise. At the implementation layer, the collaboration becomes effective. Needs for collaboration, models and information to exchange are interpreted in the IT systems' language according to technical bases previously defined between enterprises. Solutions allowing the objectives of the collaboration for an enterprise to be reached are exchanged and interpreted by other systems.

Rather than considering each layer at the same time, the methodology builds each one successively to address interoperability problems easier. The strong point is that BCM considers all the aspects of interoperability (conceptual, organisational and technology). However, this one focuses on the research of partners allowing to reach objectives defined beforehand and that require a collaboration.

These approaches are exclusively dedicated to the development of interoperability. Following the steps proposed by these methodologies, enterprises can reach desired interoperability (e.g. application interoperability with MDI). However, these do not include the following:

- Actors allowing partners to participate in the implementation of interoperability,

- The use of a tool - such as a framework - allowing partners to select adapted solution according to the identified problem

- The possibility for the partners to evaluate interoperability and to detect potential dysfunctions.

These points have to be considered by the methodology to fully involve partners through the implementation of interoperability. As a consequence, it is necessary to develop a stepby-step procedure that guides enterprises in order (1) to compose and select interoperability solutions according to their needs and (2) to evaluate their interoperability performances. Table 3 provides a comparative overview of the research works about methodologies for interoperability. It shows the four main characteristics to consider for the development of the methodology for enterprise interoperability and includes (1) the involvement of actors, (2) the consideration of interoperability measurement methods, (3) the categories of interoperability and (4) the structured approach representing the steps to perform to implement interoperability. 
Table 3. Comparative study of the different methodologies for interoperability.

\begin{tabular}{lcccc}
\hline & Actors & Interoperability measurement & Categories & Structured approach \\
\hline MDI & - & - & ++ & ++ \\
BCM & - & - & ++ & ++ \\
\hline
\end{tabular}

Table 4. General overview of works about interoperability and needs to develop the methodology for interoperability.

\begin{tabular}{|c|c|c|c|}
\hline & $\begin{array}{l}\text { Interoperability } \\
\text { framework }\end{array}$ & Interoperability measurement & Methodologies \\
\hline Advantages & $\begin{array}{l}\text { - Good identification } \\
\text { of categories of } \\
\text { interoperability } \\
\text { - Interoperability } \\
\text { solutions } \\
\text { capitalisation }\end{array}$ & $\begin{array}{l}\text { - Adapted and well-defined } \\
\text { models for each } \\
\text { interoperability category } \\
\text { - Existing metrics to } \\
\text { evaluate } \\
\text { interoperability }\end{array}$ & $\begin{array}{l}\text { - Step by step } \\
\text { methodologies to guide } \\
\text { users } \\
\text { - Consideration of all } \\
\text { aspects of } \\
\text { interoperability (BCM) }\end{array}$ \\
\hline Lacks & $\begin{array}{l}\text { - Consideration of } \\
\text { interoperability } \\
\text { levels in enterprise } \\
\text { - Consideration of } \\
\text { interoperability } \\
\text { approach(es) } \\
\text { - Approach to use the } \\
\text { framework }\end{array}$ & $\begin{array}{l}\text { - Maturity model for } \\
\text { intra-enterprise } \\
\text { interoperability } \\
\text { - Federated model to } \\
\text { consider all } \\
\text { interoperability } \\
\text { categories } \\
\text { - Tools for performance } \\
\text { measurement not adapted to } \\
\text { enterprise interoperability } \\
\text { - Tools to measure } \\
\text { compatibility }\end{array}$ & $\begin{array}{l}\text { - Expert-oriented } \\
\text { methodologies, no } \\
\text { enterprises' actors } \\
\text { - Tools to select adapted } \\
\text { solutions for specific } \\
\text { interoperability } \\
\text { approach or needs } \\
\text { - Tools to evaluate } \\
\text { interoperability }\end{array}$ \\
\hline $\begin{array}{l}\text { Needs \& } \\
\quad \text { expectations }\end{array}$ & $\begin{array}{l}\text { - To consider layers } \\
\text { where } \\
\text { interoperability } \\
\text { takes place in } \\
\text { enterprise } \\
\text { - To consider } \\
\text { interoperability } \\
\text { approaches }\end{array}$ & $\begin{array}{l}\text { - To develop a global maturity } \\
\text { models for intra-enterprise } \\
\text { - To develop compatibility } \\
\text { measurement between } \\
\text { partners } \\
\text { - To develop specific } \\
\text { interoperability } \\
\text { performance measurement } \\
\text { in agreement with } \\
\text { enterprises' criteria }\end{array}$ & $\begin{array}{l}\text { - To integrate evaluation } \\
\text { tools to evaluate } \\
\text { interoperability during } \\
\text { its implementation } \\
\text { - To integrate tools to } \\
\text { select adapted solutions } \\
\text { - To involve partners in } \\
\text { interoperability project }\end{array}$ \\
\hline
\end{tabular}

Finally, Table 4 gives an overview of the advantages and disadvantages of existing works on interoperability and regarding the three components developed in the methodology for interoperability: that is, a framework of interoperability, a method to measure interoperability, and a structured approach. From this perspective, needs and expectations, for each point that have to be carried out, are highlighted.

\section{Methodology for interoperability}

\subsection{The interoperability framework}

The enterprise interoperability framework organises and structures interoperability aspects to implement available interoperability solutions. In other words, it makes available a set 
of existing interoperability tools that solve a specific, or a set of, interoperability problems, which can occur at different levels of the enterprise (e.g. business processes). As a consequence, the interoperability framework has to consider the following:

- The problems of interoperability which enterprises face

- The existing approaches to develop interoperability

- The levels of enterprises where interoperability can be developed

- Existing interoperability solutions.

At the end, the framework has to provide adapted solutions, according to the partner's needs. The proposed enterprise interoperability framework defines three basic dimensions such as:

- Abstraction levels. These levels represent the categories of interoperability that can be developed in enterprises.

- Interoperability views. These views define the aspects of interoperability to consider at each level of enterprises.

- Interoperability approaches. These approaches define the way to solve interoperability problems.

As a consequence, after enterprises have selected an approach to develop interoperability, solutions must be proposed in order (1) to remove interoperability problems and (2) to satisfy the chosen approach.

The dimension of 'abstraction levels' takes into account the three categories of interoperability problems, which can be considered as follows.

- Conceptual level: this level is related to the syntactic and semantic aspects of systems that interoperate. This category of barriers concerns the modelling at high levels of abstraction, which take neither organisational nor technical issues into account. The syntactic aspect is related to enterprises that use different structures to represent their information and knowledge. The semantic aspect is related to the meaning of the information and knowledge used by enterprises.

- Organisational level: this level is related to the definition of responsibilities and authority so that interoperability can take place under good conditions. Responsibility is related to the definition of persons in the enterprise who are accountable for 'something' (e.g. data, process, software etc.). Authority is related to the definition of persons in enterprises who are empowered to perform some actions (e.g. creation, modification, maintenance of data). This level considers also the organisation structure.

- Technological level: this level is related to the problem of use of information technologies. This problem concerns the standards that are used to present, store, exchange, process and communicate (e.g. protocol) data through the use of computers.

The dimension of 'views' identifies various levels of enterprise where interoperability takes place. These views are based on the ATHENA Technical Framework: the business view, the process view, the service view and the data view.

- The business view refers to the harmony of working ways at the corporate level in spite of the different modes of decision-making, methods of work, legislations, culture of the company, commercial approaches and so on so that business can be developed and shared between companies.

- The process view aims at making various processes working together. A process defines a sequence of services (functions) according to a specific need of a considered company. Commonly, in a company, several processes run in interaction. In the case of a 
networked enterprise, internal processes of two companies must be connected to create a common process.

- The service view is concerned with identifying, composing and making function together with various applications (designed and implemented independently) by solving the syntactic and semantic differences, as well as finding connections between various heterogeneous databases. The term 'service' is not limited to computer-based applications but also concerns functions of the company or the networked enterprises.

- The data view refers to the means to make different data models (hierarchical, relational and so on) and different query languages working together. Moreover, their contents are organised according to conceptual schemas (i.e. vocabularies and sets of structures of data) that are related to particular applications. The interoperability of data is related to find and share information coming from heterogeneous bases, which can reside on different machines with different operating systems and database management systems.

The dimension of 'interoperability approaches' considers the three admitted approaches to develop interoperability ISO (1999): the integrated approach, the unified approach and the federated approach.

Within the situation of enterprises merging (because the need for interoperability is strong enough to lead to this solution or because of other reasons), the integrated approach is chosen. In this case, there is a standard format for all partners, and all models are developed according to this standard. It implies the format to be as rich as the models of the partners. If the need for interoperability concerns a long term-based collaboration, the unified approach may be chosen. A common meta-model across partners' models provides a mean to establish semantic equivalence. The meta-model is not an executable entity but a neutral model that allows mapping between diverse models. Finally, if interoperability is needed within a short-term collaboration project, the federated approach can be implemented. To interoperate, partners must dynamically adapt and accommodate rather than build a predetermined meta-model.

Figure 3 gives a representation of the enterprise interoperability framework, including the three basic dimensions: abstraction levels, interoperability views and interoperability approaches.

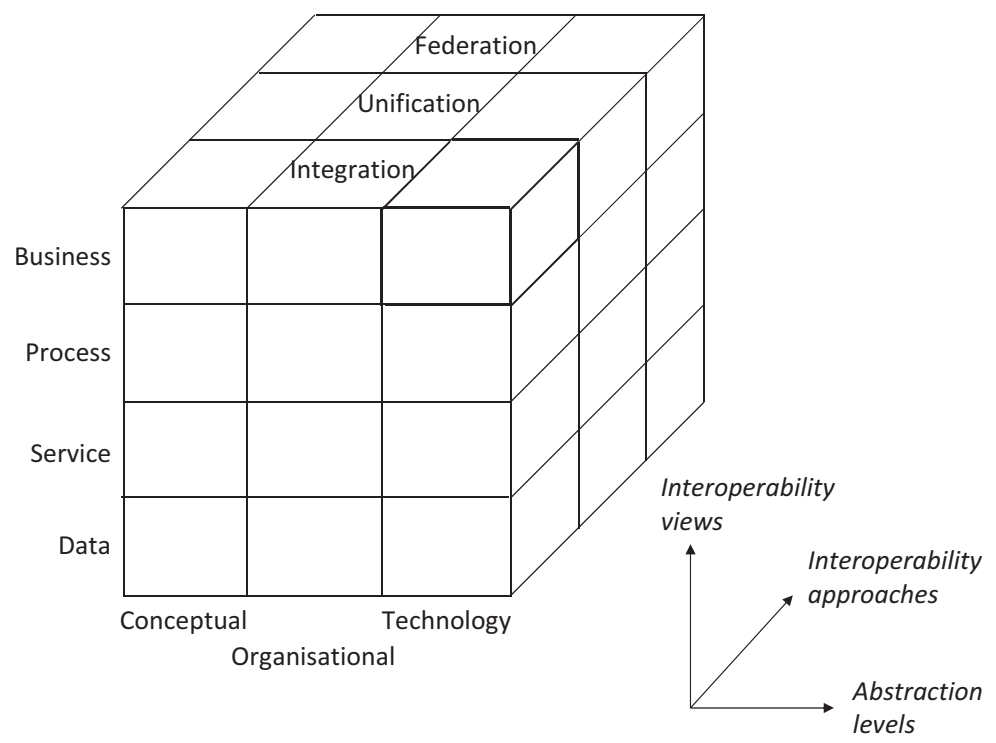

Figure 3. The enterprise interoperability framework with its three basic dimensions. 


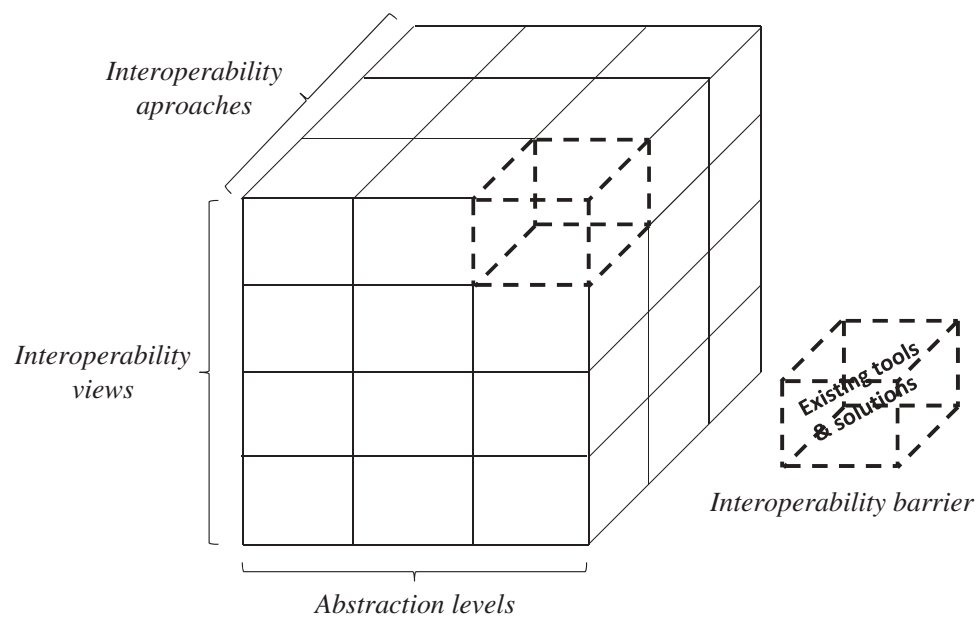

Figure 4. Representation of the space of interoperability barrier in the enterprise interoperability framework.

Finally, the intersection between a view, an abstraction level and an interoperability approach defines the space of 'interoperability barriers'. This space has to consider:

- The conceptual solutions - including reference models and architectures related to interoperability - design principles and patterns as well as approaches

- Support software to implement solutions

- Applicable solutions that would become good reusable practices.

A solution is considered as relevant to favour interoperability if it contributes to remove a barrier for a considered intersection of the three dimensions of the enterprise interoperability framework.

Figure 4 gives a representation of the space of interoperability barrier and relevant existing solutions to remove the barriers. As shown (small cube representing business view, technology level and integrated approach), an example of barrier would be two companies using two different IT infrastructures with two different IT policies; the integrated approach will concern those solutions to harmonise IT policies and to use only one agreed IT infrastructure. According to the interoperability approach that enterprises want to develop, the views where interoperability has to be implemented and the problems of interoperability to solve, adapted solutions have to be identified and proposed to enterprises.

A concrete example relating to technology solution to improve interoperability is ESB (Chappell 2004) technologies and service-oriented architectures (Krafzig, Banke, and Slama 2005; Valipour et al. 2009). These two solutions are mainly concerned with service and process interoperability at technology level through a unified or federated approaches. Indeed, from one hand, service-oriented architectures consider the harmonisation of the interactions between services, applications and processes. Relevant standards such as web service interoperability standards have been implemented to this aim. From the other hand, ESB constitute a major contribution in the middleware domain. They address interoperability issues in terms of protocols, data and so on. Based on the transformation of the messages transmitted to the services into a common model, ESBs enable 
communication between heterogeneous services and orchestrate them into a common process. The appropriate use of these two technologies would certainly improve the interoperability performance in terms of both time and cost of interoperation. Once implemented, less efforts and shorter time are required to establish interoperations between heterogeneous interoperating entities, be they data, service or process.

\subsection{The interoperability measurement}

The interoperability measurement is the second component of the methodology and deals with two kinds of measures. On one hand, the measure of interoperability can be considered a priori, that is before any collaboration. In this case, the evaluation of the interoperability is performed in an intra-enterprise context. This kind of measure is also named potentiality measurement. On the other hand, the measure of interoperability can be considered a posteriori, that is when the collaboration is carried out. In this case, the evaluation of interoperability is performed in an inter-enterprises context. This kind of measure is also named interoperability degree measurement.

The potentiality is the fact that an enterprise owns intrinsic attributes related to the three categories of interoperability (use of standards applications, enterprise models, database, and so on), which allow easy interoperation with other enterprises, in the eventuality of a partnership (Daclin, Chen, and Vallespir 2008a). In other words, potentiality is an intra-enterprise evaluation without knowing the interoperating partner. The main goal is to increase the capacity to implement interoperability and decrease the risk to meet problems during a future partnership. The enterprise interoperability potentiality model defines the evaluation of an enterprise potentiality according to the three categories of problems that impact the development of interoperability and the levels where interoperability takes place, that is business, process, service and data. For each category and each level of interoperability, five levels characterise the potentiality: (1) isolated, which represents a total incapacity to interoperate; (2) initial, where interoperability requires strong efforts that affect the partnership; (3) executable, where interoperability is possible even if the risk of encountering problems is high; (4) connectable, where interoperability is easy even if problems can appear for distant partnership; (5) interoperable, which considers the evolution of levels of interoperability in the enterprise and where the risk of meeting problems is weak. Table 5 presents the attributes - for each category of interoperability - that a given enterprise has to possess to reach an interoperable level in term of potentiality.

The goal is to evolve throughout the levels of potentiality to reach the top one. Although this evolution is compulsory to decrease the risk of meeting problems and to facilitate the implementation of interoperability, maximum potentiality does not imply full interoperability. Indeed, the use of standard tools by an enterprise does not ensure that a partner will use the same ones. Hence, problems of interoperability can still appear. For instance, the use of BPMN 2.0 (OMG 2011) - by an enterprise to model its business processes - that can be considered as modelling standard does not presage that a future partner will use this language. Nevertheless, it is very likely that other enterprises use the same language even though it can be linked to other languages easily (richness of modelling objects, use of xmi to describe model).

The interoperability degree gives information to partners about the presence (or not) of incompatibilities that can obstruct the interoperability between partners. The understanding of this evaluation allows partners to avoid and/or to correct deficiencies during 
Table 5. Enterprises' potentiality attributes.

\begin{tabular}{|c|c|c|c|}
\hline & Conceptual & Technological & Organisational \\
\hline \multirow[t]{3}{*}{ Interoperable } & $\begin{array}{l}\text { - Semantic and syntax } \\
\text { (of models) are fully } \\
\text { and well defined }\end{array}$ & $\begin{array}{l}\text { - Standards are used as } \\
\text { technical environment }\end{array}$ & $\begin{array}{l}\text { - Models, responsibility, } \\
\text { authority and skills are } \\
\text { known explicitly and updated } \\
\text { after evolution }\end{array}$ \\
\hline & $\begin{array}{l}\text { - Evolution of semantic } \\
\text { and syntax are } \\
\text { considered }\end{array}$ & $\begin{array}{l}\text { Environment is } \\
\text { maintained and } \\
\text { updated according to } \\
\text { technical evolution }\end{array}$ & $\begin{array}{l}\text { - Outsourceable information is } \\
\text { grouped and updated in } \\
\text { dedicated database }\end{array}$ \\
\hline & & & $\begin{array}{l}\text { - Access privileges to this } \\
\text { database are defined and } \\
\text { updated }\end{array}$ \\
\hline \multirow[t]{3}{*}{ Connectable } & $\begin{array}{l}\text { - Semantic and syntax } \\
\text { (of models) are fully } \\
\text { and well defined }\end{array}$ & $\begin{array}{l}\text { - Standards are used as } \\
\text { technical environment }\end{array}$ & $\begin{array}{l}\text { Models, responsibility, } \\
\text { authority and skills are } \\
\text { known explicitly }\end{array}$ \\
\hline & & & $\begin{array}{l}\text { - Outsourceable information is } \\
\text { grouped in dedicated data } \\
\text { base }\end{array}$ \\
\hline & & & $\begin{array}{l}\text { - Access privileges to this data } \\
\text { base are defined }\end{array}$ \\
\hline \multirow[t]{3}{*}{ Executable } & - Semantic and syntax & - Technical environment & - Models, responsibility, \\
\hline & $\begin{array}{l}\text { (of models) are } \\
\text { known but not fully } \\
\text { defined }\end{array}$ & is existing & $\begin{array}{l}\text { authority and skills are } \\
\text { known explicitly }\end{array}$ \\
\hline & & $\begin{array}{l}\text { - Communication } \\
\text { protocol is used to } \\
\text { exchange information }\end{array}$ & $\begin{array}{l}\text { - Outsourceable information is } \\
\text { only known }\end{array}$ \\
\hline \multirow[t]{5}{*}{ Initial } & - Semantic and syntax & - Technical environment & • Models, responsibility, \\
\hline & (of models) are & is existing & authority and skills are only \\
\hline & $\begin{array}{l}\text { known but not } \\
\text { explicitly defined }\end{array}$ & & \\
\hline & & • No communication & - Outsourceable information is \\
\hline & & $\begin{array}{l}\text { protocol is used to } \\
\text { exchange information }\end{array}$ & \\
\hline \multirow[t]{4}{*}{ Isolated } & - Semantic and syntax & - No technical & - Models are not defined \\
\hline & $\begin{array}{l}\text { (of models) are } \\
\text { unknown }\end{array}$ & $\begin{array}{l}\text { environment is } \\
\text { existing }\end{array}$ & \\
\hline & & - Exchange of & - Responsibility authority and \\
\hline & & $\begin{array}{l}\text { information can be } \\
\text { performed only } \\
\text { manually }\end{array}$ & skills are not identified \\
\hline
\end{tabular}

the collaboration. The interoperability degree includes two kinds of evaluations, such as the compatibility measurement and the performance measurement.

The compatibility measurement has to be performed during the engineering stage, that is when systems need to establish interoperability with a known partner. This measure is performed when the partner/system of the interoperation is known. The measure is done with respect to the identified problem of interoperability.

Referring to each interoperability view and interoperability problem, the objective is to check if there is incompatibility or not. With regards to the interoperability barriers, as examples, the following questions can be asked to know if incompatibility between two systems exists for some different interoperability views (Daclin, Chen, and Vallespir 
2008b). The set of questions to detect potential incompatibilities is selected according to the needs expressed by partners in terms of enterprise levels where interoperability has to be developed, and this measure is independent from interoperability approaches. Indeed, the fact that partners use, for instance, different (e.g. order, request, command and so on) meaning for their respective data does not suppose the approach selected by partners, but highlight a potential incompatibility in term of interoperability (e.g. use of exchanged data). The choice of an approach to develop interoperability will allow, in the end, a solution to be found that respect the needs expressed by partners and only for detected incompatibilities.

Conceptual compatibility for data view:

Syntactic: is the data to be exchanged expressed with the same data model? Does the data to be exchanged use a data model?

Semantic: does the data to be exchanged have the same meaning? Is the meaning of exchanged data explicitly defined?

Organisational compatibility for process view:

Process authorities: are process authorities/responsibilities clearly defined on both sides? Organisation structures: are the organisation structures of processes expressed on both sides?

Technological compatibility for business view:

Platform: are the IT platform technologies compatible? Do the partners use IT platform? Communications: do the partners use the same protocols of exchange? Do the partners use protocol of exchange?

If an incompatibility is detected, the coefficient 1 is assigned to the interoperating level and the problem that are considered. Conversely, the coefficient 0 will be applied either when no incompatibility is detected or when the view is not concerned by the development of interoperability between partners. Following this rule, the compatibility matrix, presented in Table 6, can be built. In the following matrix, the compatibility measurement is evaluated for each question presented herein. The choice of binary values allows users to identify easily and rapidly at which enterprise level, and for which category of interoperability, an incompatibility is present. These values are an indication of the existence (or not) of a problem and do not reflect the importance of the problem. For instance, an application incompatibility does not state if applications used by partners are fully incompatible or if some modules are compatible. In this sense, partners will have to identify clearly and precisely the problem to solve it at a later stage. This aspect is more deeply discussed in Section 4 below.

Table 6. The compatibility measurement matrix.

\begin{tabular}{|c|c|c|c|c|c|c|}
\hline & \multicolumn{2}{|c|}{ Conceptual } & \multicolumn{2}{|c|}{ Organisational } & \multicolumn{2}{|c|}{ Technology } \\
\hline & Syntactic & Semantic & $\begin{array}{l}\text { Authorities' } \\
\text { responsibilities }\end{array}$ & Organisation & $\begin{array}{l}\text { Platform } \\
\text { application }\end{array}$ & Communication \\
\hline Business & 0 & 0 & 0 & 0 & 1 & 0 \\
\hline Process & 0 & 0 & 1 & 1 & 0 & 0 \\
\hline Services & 0 & 0 & 0 & 0 & 0 & 0 \\
\hline Data & 0 & 1 & 0 & 0 & 0 & 0 \\
\hline
\end{tabular}


To reach the highest degree of compatibility means that all the barriers to interoperability have been removed. The inverse situation means the poorest degree of compatibility. The compatibility measure allows enterprises to know what kinds of barriers there are and what barriers have to be removed so that interoperability can be improved. The higher the number of incompatibilities, the more important the efforts of the partners to become interoperable will be.

In a similar way, the incompatibility measurement can allow companies to prioritise the actions to be taken to improve interoperability. It also allows companies to define a migration path to follow, to remove identified barriers in a progressive way. Partners have to perform their migration path and actions jointly to ensure that all barriers are really removed for each of them. Obviously, the interoperability barrier will have to be removed in accordance with the selected approach to develop interoperability.

Finally, the overall compatibility degree can be obtained with the summation of all the coefficients of compatibility in the matrix, as shown in Equation (1).

$$
d_{\text {comp }}=\sum_{i=1, j=1}^{n, 6} \operatorname{coef}_{\text {comp } i, j}, i, j, n \in \mathrm{N}^{*}
$$

where

- $d_{\text {comp }}$ is the compatibility degree between partners. For instance, a compatibility degree equal to 0 means that no problem exists between partners in terms of compatibility. A compatibility degree equal to 24 is the worst situation: there are incompatibilities issues for all views and at all abstraction levels. Precisely, it means that partners want to develop interoperability at each level, for each category, but incompatibilities are present.

- coef $_{\text {comp }}$ is the coefficient of compatibility. It is related to each view and sub-levels of abstraction (decomposition of abstraction levels as mentioned before: syntactic, semantic, authorities, responsibility, application, communication). A coefficient is equals to 0 or 1,1 meaning incompatibility.

- $i$ represents the views where interoperability is implemented.

- $j$ represents the sub-levels of abstraction.

As an example of the use of the compatibility matrix, let us consider two partners who have to exchange data related to a product. As shown by Figure 5 (upper part), partners use (1) different words to name and to describe their product (e.g. product vs. item, name vs. designation) and (2) two different data models (e.g. xml vs. EXPRESS). This statement can lead to a misunderstanding (semantic problem) between the partners and an impossibility to use the information exchanged (syntactic problem). As a consequence, two incompatibilities are highlighted in the compatibility matrix (lower part). These incompatibilities take place at the data level for the conceptual category (syntactic and semantic).

After that, the interoperability framework will be used to find the most relevant solutions to delete the barriers. This means that a set of existing solutions have been mapped to the interoperability framework beforehand. Figure 6 presents some identified interoperability solutions mapped in the interoperability framework. These solutions are positioned according to the interoperability views and the abstraction levels (i.e. category of interoperability) that a given solution considers. For instance, UEML 1.0 is considered 


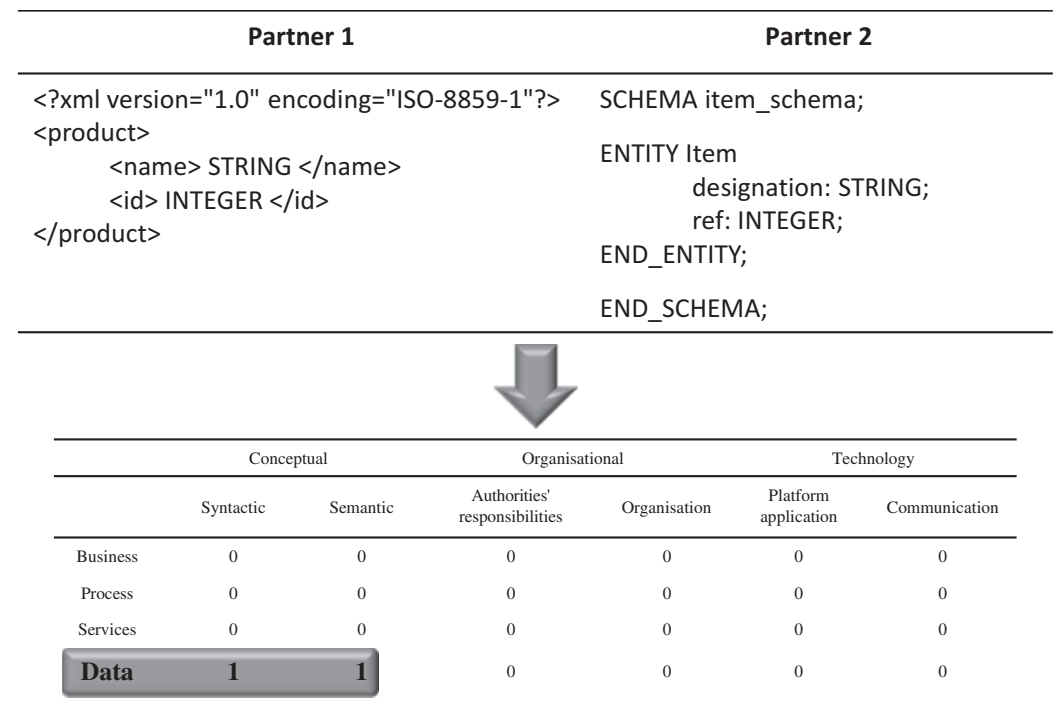

Figure 5. Example of the use of the compatibility matrix.

as an interoperability solution that allows to solve conceptual interoperability for each interoperability view. More precisely, this solution is fully adapted for partners who choose to implement interoperability from a unified approach. Taking over the previous example, partners have identified two incompatibilities at the data level for the conceptual category (precisely, semantic and syntactic). If partners choose to solve their interoperability problems following a unified approach (left side of Figure 6), the framework has to propose a set of solutions that respects their needs. Thus, for data interoperability level and conceptual category, the semantic annotation is considered as an adapted solution for this issue as well as UEML 1.0 for the syntactic issue. A complete set of interoperability solutions regarding interoperability views, abstraction levels and interoperability approaches can be found in INTEROP (2006a).

The measure of the performance of interoperation has to be performed during the operational phase, that is runtime, to evaluate the ability of interoperation between two cooperating enterprises. This performance of interoperation is based on the interoperation

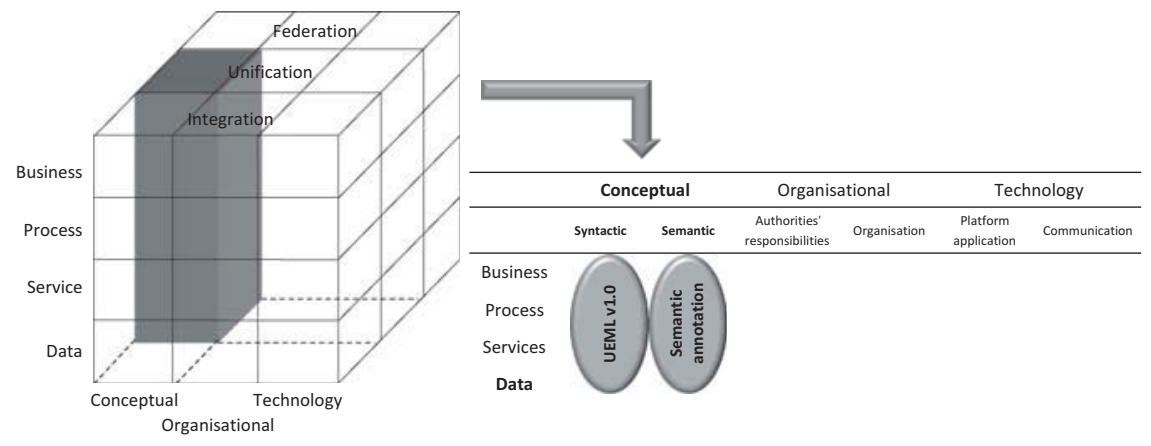

Figure 6. Enterprise interoperability framework and examples of interoperability solutions and their cover in terms of interoperability views and abstraction levels. 


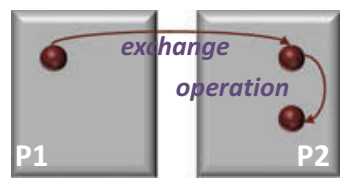

Figure 7. The interoperation cycle (exchange and operation).

cycle (Figure 7) that considers (1) a phase of exchange and (2) a phase of operation. The first phase is related to the exchange/share of data, models, decision frame, and so on. In the frame of this work, 'exchange' means that a given partner - known as the 'sender' sends (physically or not e.g. mail, phone and so on) or makes available data, models and so on for the interoperation partner. For instance, a sender transmits a set of data required by a receiver. The second phase is related to the operation of the exchanged/shared data, models, decision frame and so on by the partner receiver. In the frame of this work, 'operation' means that a given partner known as the 'receiver' is able to use for a particular task the data, models and so on provided by a sender. For instance, when a receiver receives the data, it understands and it is able to process this one to perform a given task.

Classical criteria such as cost, time and quality are used to measure the performance with respect to problems and views during a basic interoperation cycle. The following parts present each criterion in details, including an example to illustrate their application. This example considers interoperation between a partner P1 (sender) that has to send a set of four data (e.g. parts list, routing sheet, code, plan) and a partner P2 that requests these data to perform its own task (e.g. computer numeric control machining). These data are sent by email.

The cost of interoperation $\left(C_{\mathrm{in}}\right)$ represents the cost engaged by the partners to perform an interoperation cycle. It is made of the cost of exchange $\left(C_{\mathrm{ex}}\right)$ and the cost of operation $\left(C_{\mathrm{op}}\right)$. The evaluation of the performance of interoperation, in terms of cost, corresponds to the comparison of the real cost of exchange and operation with the cost of exchange and operation that enterprises wish to engage. If one of these real costs is greater than the expected costs, then there is a deficiency. The cost of exchange and the cost of operation are then expressed as

$$
\begin{gathered}
C_{\text {in }}=C_{\text {ex }}+C_{\text {op }} \\
C_{\text {ex }}=C_{\text {iniex }}-C_{\text {effex }} \\
C_{\text {op }}=C_{\text {iniop }}-C_{\text {effop }}
\end{gathered}
$$

where

- $C_{\text {in }}$, the overall cost of interoperation. If the cost of interoperation is less than 0 , the criterion is not respected (partners have to correct incriminated criteria). Conversely, a cost of interoperation greater than or equal to 0 means that this criterion is respected (a given criterion can offset the other and partners can accept this statement).

- $C_{\text {ex }}$, the cost of exchange. It represents the difference between the initial cost allocated to exchange and the real cost of exchange. 
Table 7. Example of the calculus of cost of interoperation according to its criteria.

\begin{tabular}{lll}
$\begin{array}{l}\text { Performance } \\
\text { type }\end{array}$ & Details & \multicolumn{1}{c}{ Description } \\
\hline $\begin{array}{l}\text { Cost of } \\
\text { exchange }\end{array}$ & $C_{\mathrm{ex}}=0$ & $\begin{array}{l}C_{\mathrm{ex}}=0, \text { cost of emailing is considered as } \\
\text { negligible by the sender }\end{array}$ \\
$\begin{array}{c}\text { Cost of } \\
\text { operation }\end{array}$ & $C_{\mathrm{op}}=C_{\text {iniop }}-C_{\text {effop }}=380-380=0 \begin{array}{l}C_{\text {iniop }}=380, \text { the receiver has allocated this } \\
\text { cost to exploit data } \\
C_{\text {effop }}=380, \text { parts list and routing sheet } \\
\text { has to be transformed to be exploited by } \\
\text { software used by receiver. An IT Services } \\
\text { \& Software Engineering company has } \\
\text { performed the transformation sheets } \\
\text { (charged } 380 € / \text { day) }\end{array}$ \\
\hline
\end{tabular}

- $C_{\text {iniex }}$, the initial cost allocated for exchange.

- $C_{\text {effex }}$, the real cost of exchange.

- $C_{\mathrm{op}}$, the cost of operation. It represents the difference between the initial cost allocated to operation and the real cost of operation.

- $C_{\text {iniop }}$, the initial cost allocated for operation.

- $C_{\text {effop }}$, the real cost of operation.

Following the example described previously, it is possible to calculate the cost of interoperation. Table 7 shows the calculation of the cost of exchange and the cost of operation.

The duration of interoperation $\left(T_{\mathrm{in}}\right)$ corresponds to the duration between the date at which information is sent and the date at which the requested information is effectively exploitable. The principle here is similar to the one applied for the cost. The duration of interoperation is broken down into two intervals such as the duration of exchange $\left(T_{\mathrm{ex}}\right)$ and the duration of operation $\left(T_{\mathrm{op}}\right)$. The equations given hereafter represent the duration of interoperation according to this decomposition.

$$
\begin{gathered}
T_{\text {in }}=T_{\text {ex }}+T_{\text {op }} \\
T_{\text {ex }}=T_{\text {rec } 2}-T_{\text {em } 1} \\
T_{\text {op }}=T_{\text {op } 2}-T_{\text {rec } 2}
\end{gathered}
$$

where

- $T_{\mathrm{in}}$, the overall duration of interoperation. If the duration of interoperation is greater than expected duration of interoperation, the criterion is not respected (partners have to correct incriminated criteria). If the duration of interoperation is less than or equal to expected duration of interoperation, then the criterion is respected (a given criterion can offset the other and partners can accept this statement).

- $T_{\mathrm{ex}}$, the duration of exchange. It represents the time measurement between the date of the emission of information (partner 1) and the date of reception of the information (partner 2). 
Table 8. Example of the calculus of duration of interoperation according to its criteria.

\begin{tabular}{|c|c|c|}
\hline $\begin{array}{l}\text { Performance } \\
\text { type }\end{array}$ & Details & Description \\
\hline $\begin{array}{r}\text { Duration of } \\
\text { exchange }\end{array}$ & $T_{\mathrm{ex}}=T_{\mathrm{rec} 2}-T_{\mathrm{em} 1}=3.50 \mathrm{pm}-3.00 \mathrm{pm}=50 \mathrm{~min}$ & $\begin{array}{l}T_{\text {rec } 2}=3.50 \mathrm{pm} \text {, the receiver } \\
\text { receipts data at this date } \\
T_{\text {em } 1}=3.00 \mathrm{pm} \text {, the send starts } \\
\text { to transmit at this date }\end{array}$ \\
\hline $\begin{array}{r}\text { Duration of } \\
\text { operation }\end{array}$ & $T_{\mathrm{op}}=T_{\mathrm{op} 2}-T_{\mathrm{rec} 2}=4.00 \mathrm{pm}-3.50 \mathrm{pm}=10 \mathrm{~min}$ & $\begin{array}{l}T_{\mathrm{op} 2}=4.00 \mathrm{pm} \text {, after treatment } \\
\text { the receiver can exploit data } \\
\text { at this date } \\
T_{\text {rec } 2=3.50 \mathrm{pm} \text {, the receiver }} \\
\text { receipts data at this date }\end{array}$ \\
\hline
\end{tabular}

- $T_{\text {op, }}$, the duration of operation. It represents the time measurement between the date of the reception of information and the date of operation, that is information can be really exploited.

- $T_{\text {rec2 } 2}$, the date of reception by partner 2 .

- $T_{\mathrm{em} 1}$, the date of emission by partner 1 .

- $T_{\mathrm{op} 2}$, the date of operation by partner 2 .

The evaluation of the duration of interoperation corresponds to the comparison of the real duration of exchange and operation with the duration of exchange and operation expected by the partners. If none of these durations are greater than those expected, there is no deficiency and the durations of exchange and operation are correct.

Once again, let us consider the example previously introduced to calculate the duration of interoperation. Table 8 presents this evaluation and the description of the terms belonging to these criteria.

The quality of interoperation $\left(Q_{\text {in }}\right)$ takes three kinds of quality into consideration: (1) the quality of exchange, (2) the quality of operation and (3) the conformity. The quality of exchange $\left(Q_{\mathrm{ex}}\right)$ draws up if the exchange is correctly performed, that is if information sent to a partner succeeds. The quality of operation $\left(Q_{\mathrm{op}}\right)$ represents the number of receptions by a partner by comparison with the number of requests. For instance, a higher amount of receptions (difficulty to process all the information) or lower amount (shortage of information) to the number of requests means a deficiency. Finally, the conformity ( $Q_{\text {conf }}$ ) corresponds to the operation of the information, that is if the fact that the information received is directly exploitable or not. These three types of quality can be expressed according to the following equations:

$$
\begin{gathered}
Q_{\text {in }}=Q_{\text {ex }}+\left|Q_{\text {op }}\right|+Q_{\text {conf }} \\
Q_{\text {ex }}=N_{\text {eff }}-N_{\text {succ }} \\
Q_{\text {op }}=N_{\text {req }}-N_{\text {rec }} \\
Q_{\text {conf }}=N_{\text {rec }}-N_{\text {conf }}
\end{gathered}
$$

where 
- $Q_{\text {in }}$, the overall quality of interoperation. If the quality of interoperation is greater than expected, quality of interoperation, the criterion is not respected (partners have to correct incriminated criteria). If the quality of interoperation is less than or equal to expected quality of interoperation, then the criterion is respected (a given criterion can offset the other and partners can accept this statement).

- $Q_{\text {ex }}$, the quality of exchange. It represents the difference between the total number of sendings and the number of successful sendings.

- $N_{\text {eff }}$, the number of effective sendings.

- $N_{\text {succ, }}$, the number of sendings successfully completed.

- $Q_{\text {op }}$, the quality of operation. It represents the difference between the number of requests and the number of receptions.

- $N_{\text {req, }}$, the number of requests.

- $N_{\text {rec }}$, the number of receptions.

- $Q_{\text {conf, }}$ the conformity. It represents the difference between the total number of receptions and the number of conform receptions, that is workable without intermediary.

- $N_{\text {conf }}$, the number of conform receptions.

Finally, to evaluate the performance of interoperation in terms of quality, it is necessary to compare each real quality criterion with quality criterion expected by partners. If none of these quality levels is different to the expected one, there is no deficiency. Otherwise, the deficient criterion has to be identified to start corrective actions.

According to the example, each criterion of the quality of interoperation can be calculated. Table 9 presents this evaluation and the description of the terms.

The performance assessment allows partners to know their global degree of performance according to the three criteria: time, quality, and cost. If a deficiency is detected, the coefficient 1 is assigned to the considered performance attribute. Conversely, the coefficient 0 will be applied when no deficiency is detected. Following this rule of interpretation, the vector of interoperation performance can be built (Table 10). Based on the example, this means that no gaps are observed on interoperation performance criteria, excepted on the criteria $T_{\mathrm{ex}}$ (duration of exchange). For instance, because of a capacity restriction, the sender has performed two sendings, leading to a duration of exchange (50 min, preparation of folders and sending) greater than expected. Once again, binary values are easily readable and understandable for users, but without indicating the importance of the gap in the case of a deficiency is detected. Thus, when a performance of

Table 9. Example of the calculus of quality of interoperation according to its criteria.

\begin{tabular}{lll}
\hline $\begin{array}{l}\text { Performance } \\
\text { type }\end{array}$ & \multicolumn{1}{c}{ Details } & \multicolumn{1}{c}{ Description } \\
\hline $\begin{array}{l}\text { Quality of } \\
\text { exchange }\end{array}$ & $Q_{\text {ex }}=N_{\text {eff }}-N_{\text {succ }}=2-2=0$ & $\begin{array}{l}N_{\text {eff }}=2, \text { sender has performed } 2 \text { sendings } \\
N_{\text {succ }}=2, \text { sender has asked a confirmation of } \\
\text { reception }\end{array}$ \\
$\begin{array}{lll}\text { Quality of } \\
\text { operation }\end{array}$ & $Q_{\text {op }}=N_{\text {req }}-N_{\text {rec }}=4-4=0$ & $\begin{array}{l}N_{\text {req }}=4, \text { the receiver has requested } 4 \text { data } \\
N_{\text {rec }}=4, \text { the receiver has received } 4 \text { data }\end{array}$ \\
$\begin{array}{ll}\text { Conformity } \\
\text { conf }\end{array}=N_{\text {rec }}-N_{\text {conf }}=4-4=0$ & $\begin{array}{l}N_{\text {rec }}=4, \text { the receiver has received } 4 \text { data } \\
N_{\text {conf }}=4, \text { the data are conform to those } \\
\text { expected }\end{array}$ \\
\hline
\end{tabular}


Table 10. The vector of interoperation performance.

\begin{tabular}{|c|c|c|c|c|c|c|}
\hline \multicolumn{2}{|c|}{$C_{\text {in }}$} & \multicolumn{2}{|c|}{$T_{\text {in }}$} & \multicolumn{3}{|c|}{$Q_{\text {in }}$} \\
\hline$C_{\mathrm{ex}}$ & $C_{\mathrm{op}}$ & $T_{\mathrm{ex}}$ & $T_{\mathrm{op}}$ & $Q_{\mathrm{ex}}$ & $Q_{\mathrm{op}}$ & $Q_{\mathrm{c}}$ \\
\hline 0 & 0 & 1 & 0 & 0 & 0 & 0 \\
\hline
\end{tabular}

interoperation is unsatisfying, the incriminated criteria will have to be clearly located and fully described.

The highest degree of performance (none of the three criteria measures differs from the expected results) means that no deficiency appears during the collaboration. The inverse situation (at least one of the three criteria measures differs from the expected results) means that deficiency(ies) exist(s) between partners.

The overall degree of performance can be obtained with the summation of all the coefficients of performance in the matrix, as shown in Equation (12).

$$
p_{\text {int }}=\sum_{\text {att }=1}^{7} \operatorname{coef}_{\text {att }}
$$

where

- $p_{\text {int }}$ represents the performance of interoperation between partners.

- coef $_{\text {att }}$ is the coefficient assigned to the performances attributes. A coefficient is equal to 0 or 1,1 meaning a deficiency on the given attribute.

- att represents the attributes of performance that are concerned $\left(C_{\mathrm{ex}}, C_{\mathrm{op}}, T_{\mathrm{ex}}\right.$ etc. $)$.

It is notable that the measurement of performances can be done against some pre-agreed criteria or agreements. For example, evaluating interoperability between services can be supported thanks to service level agreements (SLAs) (Verma 1999; Desai 2010) that define a kind of contract between services. The contracts express objectives such as the duration, performance, etc. These contracts are negotiated before the interaction between the provider and the consumer of a service takes place. As such, the required quality, time and cost between a service interoperation can be agreed between two entities. Using SLAs in a company can indeed improve its interoperability potential and maturity, but this must be carried out before evaluating the performance.

\subsection{The structured approach}

The structured approach aims at defining the main steps to follow in a sequential way, with the possibility to perform several iterations if needed. Four main steps and activities are identified.

Step 1. Definition of objectives and needs. Regarding the objectives, partners have to identify the views where interoperability is implemented. Partners have also to define the performance of interoperability that is targeted, evaluating the feasibility and cost as well as defining project planning. In terms of needs, it is about the selection of the approach to develop interoperability. 
Step 2. Analysis of the existing systems. The main goal of this phase is to identify actors, applications and systems that are involved and interoperability problems that are encountered.

Step 3. Select and combine solutions. This consists in searching and selecting available interoperability solution elements with the support of the interoperability framework. Selected solutions have to respect objectives and needs expressed at the first step of the approach.

Step 4. Implementation and test. In this phase, solutions to remove the barriers will be implemented, tested and evaluated. The results are compared with the objectives initially defined.

Furthermore, depending on whether the methodology is being applied to an individual company (a) or between partners (b), each phase will involve the use of the EIPM (Enterprise Interoperability Potentiality Measurement) or EIDM (Enterprise Interoperability Degree Measurement). Table 11 presents the details of actions to be done in the case of the methodology is applied to a given company or between companies.

The most crucial activity is to identify the problems to achieve the interoperability degree targeted by the companies. Identifying barriers is only concerned with the elements that need to be shared and exchanged between two systems/companies. Interoperability requires a common basis for those elements.

Once the solution(s) is(are) implemented, a new measurement needs to be done to verify if all barriers are effectively removed using the proposed solution(s). In some cases, the interoperability is improved but some incompatibilities still remain. A new iteration is required to adapt the solution or use other solutions until all barriers are fully removed. Performance measures may also be required at the test phase.

Table 11. Detail of methodology steps according to its implementation.

\begin{tabular}{lcc}
\hline & \multicolumn{2}{c}{ Application of the methodology } \\
\cline { 2 - 3 } Steps & \multicolumn{1}{c}{ Individual company (a) } & \multicolumn{1}{c}{ Between partners (b) } \\
\hline $\begin{array}{l}\text { 1. Definition of } \\
\text { objectives and } \\
\text { needs }\end{array}$ & $\begin{array}{c}\text { To define needs of interoperability for } \\
\text { each area of concern defined in the } \\
\text { EIPM }\end{array}$ & $\begin{array}{c}\text { To define needs of interoperability } \\
\text { in terms of enterprise level and } \\
\text { approach (integrated, unified, and } \\
\text { federated) as defined in the }\end{array}$ \\
$\begin{array}{l}\text { 2. Analysis of the } \\
\text { existing systems }\end{array}$ & $\begin{array}{c}\text { To analyse the 'as-is' situation; to define } \\
\text { the 'to-be' situation and the gaps } \\
\text { between them }\end{array}$ & $\begin{array}{l}\text { To identify problems of } \\
\text { interoperability, to measure } \\
\text { existing interoperability degree } \\
\text { using EIDM (compatibility } \\
\text { measurement), analyse strong } \\
\text { and weak points }\end{array}$ \\
$\begin{array}{l}\text { 3. Selection and } \\
\text { combination of } \\
\text { solutions }\end{array}$ & $\begin{array}{c}\text { To provide recommendation in the form } \\
\text { of a conceptual solution (i.e., standards } \\
\text { to be adopted, solutions to use and } \\
\text { where to apply them, etc.) }\end{array}$ & $\begin{array}{l}\text { To combine and construct a } \\
\text { company-specific technical } \\
\text { solution that takes the objectives } \\
\text { and constraints of the company } \\
\text { into consideration }\end{array}$ \\
$\begin{array}{l}\text { 4. Implementation } \\
\text { and test }\end{array}$ & $\begin{array}{c}\text { To implement the technical solutions that } \\
\text { have been elaborated during step 3 }\end{array}$ & $\begin{array}{l}\text { To carry out performance measures } \\
\text { and compare the results to the } \\
\text { targeted interoperability degree } \\
\text { and performance }\end{array}$
\end{tabular}


This methodology is also participative and four groups of actors are defined (these groups are based on the GRAI methodology (Chen and Doumeingts 1996; Doumeingts, Vallespir, and Chen 1998):

- The project board regroups the top-level management members of the company. They give the objectives of the project. This group is involved in the first step to identify precisely objectives and needs and in the last step to validate the overall interoperability project.

- The synthesis group is made of the main responsible persons of the company. They ensure the follow-up of the project and check the results at various stages. This group is involved into the second step to determine tools (e.g. models, application) that are used as well as actors involved into interoperation. It is also implicated in the third step to search and choose interoperability solutions.

- The specialist group consists of experts in interoperability and methodology. They give advices to the synthesis group, build various models and perform analysis. This group is involved in the third step to validate interoperability solution selected by the synthesis group.

- The interviewees group is built from company end-users to be interviewed by specialists. They provide information needed by the other groups. This group is involved each time that another group requests for any further information.

It is necessary to plan the meetings and tasks to perform. Usually, several iterations are needed to get a validated analysis and good models representing the 'as-is' situation of the company.

The proposed methodology for interoperability, including the set of its components and their consistent relationships, is represented in Figure 8.

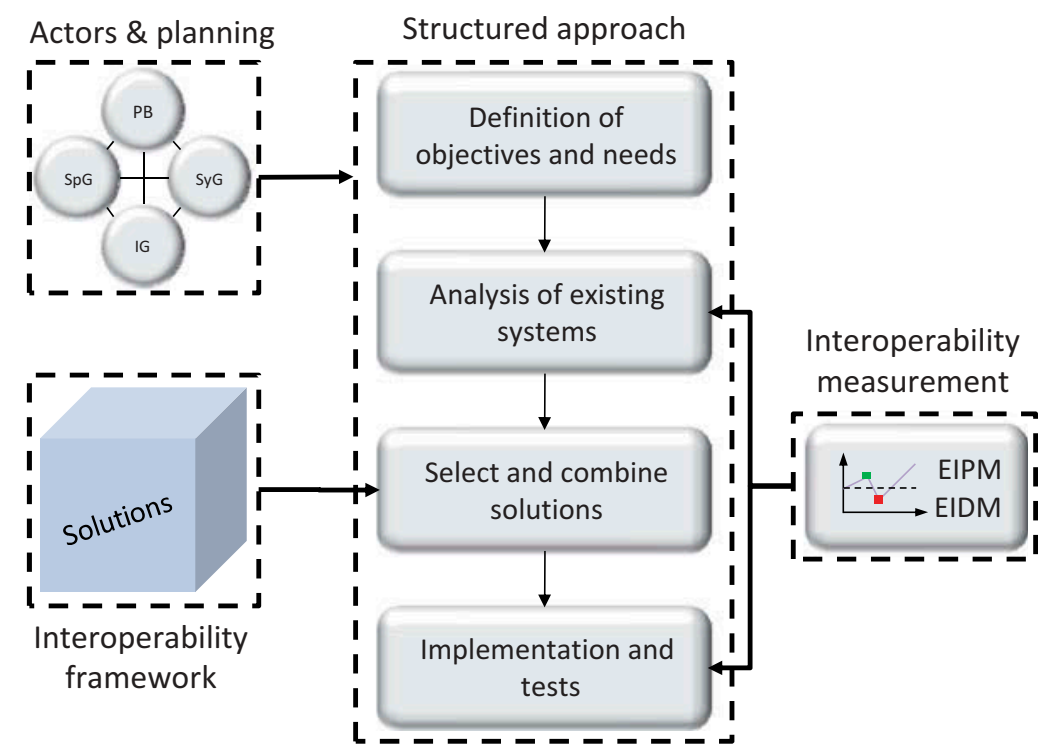

Figure 8. The structure of the methodology for enterprise interoperability. 


\section{Discussion about the methodology for interoperability}

As shown in the previous sections, the proposed methodology for interoperability is supported by three basic components (structured approach, enterprise interoperability framework and interoperability measurement). Although the structured approach is presented as a sequential execution of different steps, partners have the possibility to iterate throughout these steps. Thus, if the step 'implementation and test', for instance, does not meet the expected performances (or incompatibilities are always existing between partners), it is possible either to 'select or combine other solutions' or to 'redefine objectives and needs' and to repeat until objectives and needs are satisfied.

As far as interoperability measurement is concerned, this component is mainly used during methodology application to implement interoperability. However, it can also be used during partnership to monitor possible evolutions in terms of interoperability (e.g. catalectic failure to exchange, data modification/evolution etc.). Once an interoperability problem, or change, has been detected, corrective actions have to be performed to overcome the issue. Regarding this dynamic aspect, we can also mention recent work about interoperability problems detection 'on the fly' - especially in collaborative processes (for the organisational interoperability category) - that is based on the use of formal verification techniques to verify interoperability requirements (Mallek, Daclin, and Chapurlat 2012).

Regarding metrics used in the compatibility matrix, these are binary at this stage (1 when an incompatibility is detected, 0 otherwise). The use of binary values can seem straightforward; nevertheless, the main objective of such a measure is to highlight the presence of interoperability problem whether complete or partial. For instance, although the meaning of data to exchange by partners is partially known and explicitly defined and some of these are perfectly exchangeable and exploitable, the problem is still present. Obviously, it is then necessary to identify precisely which data are concerned and use a solution to improve the situation (e.g. semantic annotation, ontology (INTEROP 2006b)). However, it could be interesting to allow partners to refine the evaluation of compatibility that can be useful (1) to know the precise importance of a problem and further (2) to prioritise the implementation of a solution for a given problem in comparison to other identified problems. In this sense, we can mention works related to qualitative reasoning (Gonzalez-Baixauli, Do Prado Leite, and Mylopoulos 2004) and, further, the fuzzy sets (Zadeh 1978; Bana e Costa and Chagas 2004). These methods are fully adapted to improve the two points mentioned above; nonetheless, the use of fuzzy sets will need some further investigations and research. For instance, fuzzy sets require to define membership functions (define and generalise membership functions that are proper to enterprises and instead of enterprises can be hazardous) and preference models (according to information given by enterprises to extract weights and interactions that are specific to each enterprise). This can be considered as a perspective for future research.

Therefore, keep in mind that (1) each application of the methodology is specific to the partnership (and partners) and depends strongly on the companies' needs and (2) each identified problem will have to be solved. Thus, it would be preferable in a first time to adopt the pair $\{0,1\}$ and allow partners to refine their evaluation when they evaluate their degree of compatibility (analysis of the existing systems). Nevertheless, the adoption of a complex multi-level evaluation scale (such as fuzzy set method) will not be necessity to reconsider the methodology, and its underlying concepts will remain valid. 


\section{Application example of the methodology}

\subsection{Context}

The following application example is based on a case study that has been proposed and performed by Singular Software (Singular Enterprise 2003) within the Network of Excellence INTEROP (Interoperability Research for Networked Enterprises Applications and Software; FP6, IS 508011). This application is related to the implementation of interoperability between the company Telco and its dealers. Demo TelCo SA is part of the Greek group of companies Telco. This group specialises in telecommunications, production and distribution of batteries.

To distribute its products and services, Telco develops partnership with dealers. In this way, Telco call upon two kinds of dealers such as:

- Franchisees, that are only supplied by Telco

- Independent dealers, that are in relation with Telco and other suppliers.

The application focuses on the interoperability between an independent dealer and Telco. Precisely, the two partners want to implement interoperability between the 'sales department' of Telco and the 'purchase department' of the independent dealer. As a consequence, it is necessary to ensure the exchange and the operation of all information throughout the order process where interactions are numerous.

\subsection{Application}

\subsubsection{Definition of objectives and needs}

The partners' objectives are to remove all existing incompatibilities. These objectives are related to interoperability in terms of (1) data (orders, invoices etc.), (2) processes (coordination and synchronisation of partner's activities to process orders and payments) and (3) business (decisional aspect).

Partners have also defined their objectives in terms of interoperation performances. The cost of interoperation, related to the exchange of information that is required to perform an order, does not have to exceed $5 \%$ of the budget allocated to the exchange of information. The cost of operation (i.e. the cost to exploit exchanged information) does not have to exceed $10 \%$ of the budget allocated to implement new tool. For the duration of interoperation, orders are performed each day and this action has to be over in the late morning to ensure shipment activities in the afternoon. Thus, the objective for partners is that the duration of exchange and the duration of operation do not have to exceed one quarter of the duration to perform a complete order processing. Finally, no deficiencies have to be detected on each attribute of the quality of interoperation.

In terms of needs, the collaboration between Telco and its dealers is long-term oriented. However, partners wish to be able to stop the partnership easily. In this way, the implementation of interoperability does not lead to strong modification of their tools and methods of work. Therefore, if incompatibilities between partners are identified, the solutions deployed with the unified approach are preferred.

\subsubsection{Analysis of the existing systems}

The analysis of the existing system is based upon the information provided by Telco and regarding the order process, a scenario can be established from this information. 
Table 12. Application of the rule of distribution.

\begin{tabular}{lccc}
\hline & Ordered quantity & Available quantity & Provided quantity \\
\hline Dealer 1 & 3 & 3 & 2 \\
Dealer 2 & 2 & & 1 \\
\hline
\end{tabular}

When a dealer needs products, it sends an order to the sales department of Telco. Every day, Telco receives numerous orders from its dealers and has implemented a rule of distribution. This rule is based on the proportionality between the available quantities of products and the quantities ordered by dealers. If the overall quantity ordered is available, all orders are fully performed. If the quantity is not sufficient for all orders, the sales department decides which order will be fulfilled. It is to be noted that franchisees have the priority for their orders. The decision of the distribution is taken by those responsible of the sales department of Telco. For independent dealers, the rule is that they will receive a quantity proportional to the ordered and available. Table 12 gives an illustration of the rule of distribution.

Thus, after receiving orders, Telco controls the available quantity of products and applies its own rule to adjust orders. If the quantity is available, the distribution is launched and the logistic department is informed to deliver items (this process is not described here). If the quantity is unavailable, the order is corrected, the distribution is launched and the logistic department is informed to deliver items. Then, Telco prepares and sends an invoice to the dealer. Finally, the dealer issues a direct debt authorisation and sends it to Telco which makes the debit for its payment.

Figure 9 gives a representation of the scenario of an order process between the actors belonging to Telco and the actors belonging to the dealer. In this scenario, the pools represent the organisations that interoperate (Telco and dealer). The lanes represent department within Telco (sales department and logistics department). This process modelled with BPMN 2.0 - describes the 'as-is' situation in term of activities performed by partners. The information, about the way that activities are performed (e.g. rule to control of available quantity and decision), about the sequencing of activities, about information exchanged between partners (e.g. invoice), are collected and highlighted.

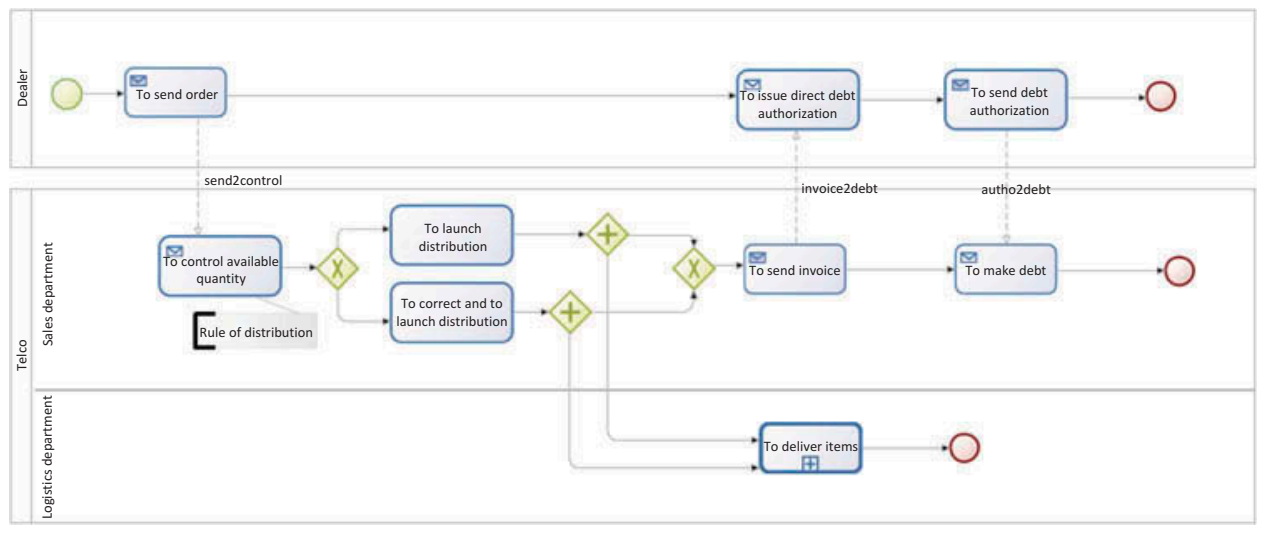

Figure 9. Scenario of order between Telco and a dealer. 
Thus, this process remains at descriptive and analytic levels and is not meant to be automatised and executed as workflow. Although both companies use some software applications to support their activities, some activities are still performed by humans; there is no direct connection between those applications across companies. Consequently, there is no exchange of services (applications) between the two companies.

The analysis of the scenario and information given by partners to realise an order makes possible the detection of existing incompatibilities. Thus, five incompatibilities located on three different views have been highlighted.

- At data level, a conceptual incompatibility is identified. This incompatibility is related to the semantic and syntactic problems. On the one hand, partners use different data models to represent their information. On the other hand, they use different data semantic (e.g. an 'order' for the dealer corresponds to a 'request' for Telco). This situation leads to difficulties for the partners to exploit different data that are exchanged.

- At process level, two kinds of incompatibilities are identified: an organisational incompatibility and a conceptual incompatibility. Regarding the organisational incompatibility, there is no explicit process (i.e. modelled) that defines the treatment of an order between partners. The process presented hereinbefore is based on the information given by partners and their experience. As a consequence, partners do not have any process that represents and defines clearly the different activities involved in an order treatment. Regarding the conceptual incompatibility, partners use different modelling languages to represent their internal process. In this case, it is difficult to build a common order process.

- At business level, an organisational incompatibility is identified. As observed in the 'analysis of the existing systems' step, the treatment of an order by Telco requires a specific procedure. Indeed, Telco uses a rule of distribution based on the available quantity, the proportionality and the ordered quantity. In other words, the decision of distribution is made only by Telco, without any consultations with the dealer. As a consequence, a dealer can send an order that is not respected. It is necessary to implement interoperability between partners at decisional level to allow a dealer to modify, faster, its orders with other suppliers.

The incompatibilities identified above are described in Table 13, according to the interoperability views that are concerned and the abstraction level.

The incompatibilities are shown on the process and positioned in the compatibility matrix (Figure 10). From this identification, partners have the possibility to choose adapted solutions to remove incompatibilities and respect the selected approach.

It is notable that the case study is performed for the implementation of a new partnership between Telco and a dealer. In this case, a measure of the performance of interoperation cannot be achieved at this stage. This measure will be performed through the phase of 'implementation and tests'.

\subsubsection{Selection of interoperability solutions}

The selection of solutions is supported by the interoperability framework. The solutions selected and implemented by partners have to remove all existing incompatibilities identified and respect the chosen approach (i.e. unified). 
Table 13. Description of interoperability problems for all interoperability views at all abstraction levels.

\begin{tabular}{|c|c|c|}
\hline $\begin{array}{l}\text { Interoperability } \\
\text { view }\end{array}$ & Abstraction level & Description of incompatibility \\
\hline Data & Conceptual (semantic) & $\begin{array}{l}\text { - Semantic of exchanged data is different. } \\
\text { Impossible to exploit exchanged data. }\end{array}$ \\
\hline Data & Conceptual (syntactic) & $\begin{array}{l}\text { - Different data model is used by partners. } \\
\text { > Impossible to exploit exchanged data. }\end{array}$ \\
\hline Process & Conceptual (syntactic) & $\begin{array}{l}\text { - Different process modelling languages are used } \\
\text { by partners. } \\
>\text { Impossible to model and to exploit a common } \\
\text { process model. }\end{array}$ \\
\hline Process & Organisational & $\begin{array}{l}\text { - No common process is modelled } \\
\text { - Responsibilities during the treatment of an order } \\
\text { are not identified } \\
>\text { Impossible to improve the treatment of an order. }\end{array}$ \\
\hline Business & Organisational & $\begin{array}{l}\text { - No decision frames (including objectives, } \\
\text { decision variables and constraints) are explicitly } \\
\text { described by partners. } \\
\text { - No information is exchanged to make common } \\
\text { decision. } \\
\text { - Risk of making a decision that does not satisfy all } \\
\text { partners. }\end{array}$ \\
\hline
\end{tabular}

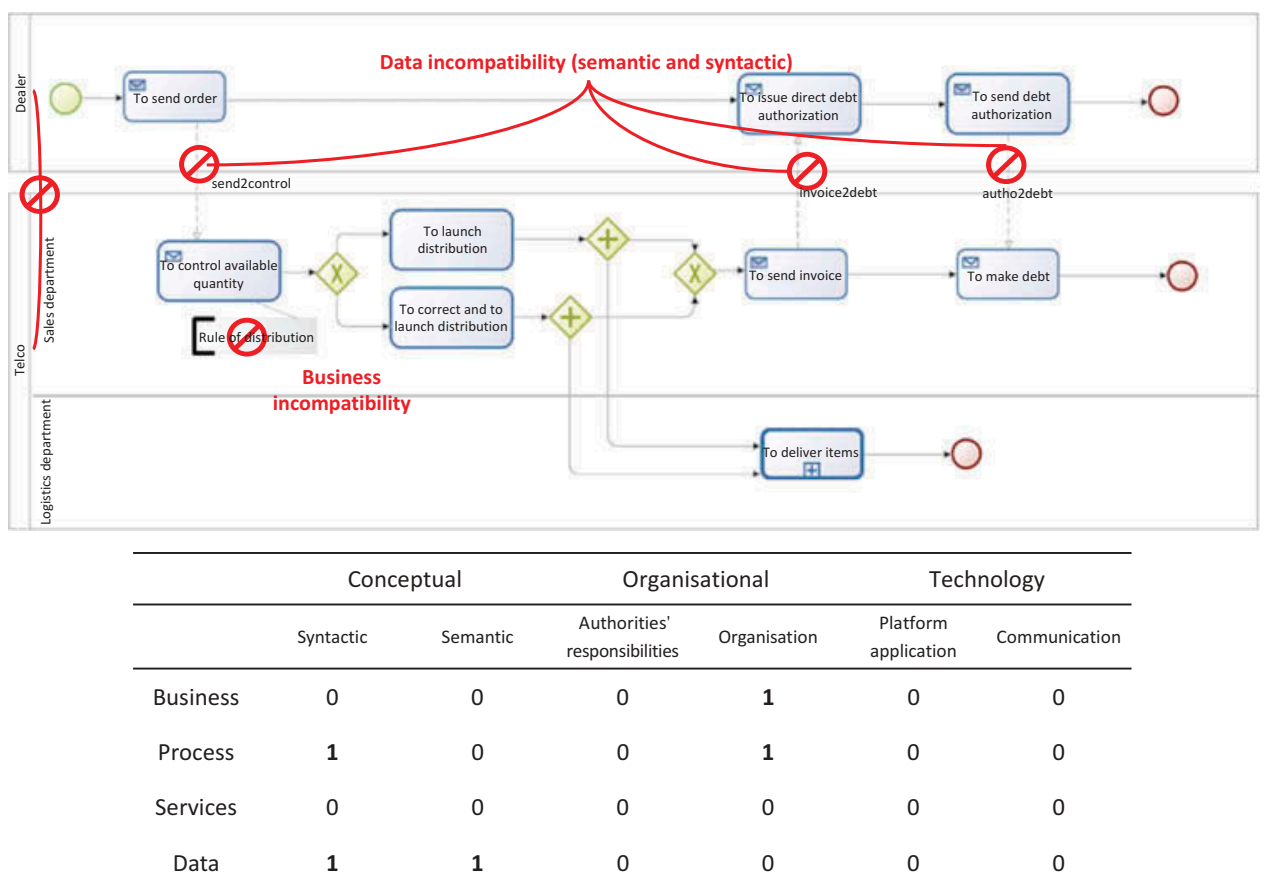

Figure 10. Scenario and identification of problems of interoperability in compatibility matrix. 
- As far as syntactic and semantic problems are concerned, the semantic annotation related to ontology allows to map partners' vocabulary and format at data level (ATHENA 2006).

- For the conceptual problem (syntactic) at process level, a meta-model may be used to propose a 'process dimension' that includes basic process modelling constructs such as activities, flows, gateways, events... Thus, rules will have to be defined to allow the mapping between the constructs of each used modelling language to use it as an exchange format. A meta-model such as POP* (ATHENA 2005b) can be chosen. These rules and transformations are not directly implemented and performed by partners, who will act as end-users, but automated through a dedicated software.

- Regarding the organisational problem at process level, partners have to organise and to model the order process. This model allows (1) a precise and a global view of the different activities involved in the order process and (2) to avoid some deficiencies during the execution (e.g. loss of time).

- At the business level, for the organisational problem, an approach defining principles that guide partners to make an acceptable decision not only for a given partner but also for its interoperation partners has been defined and implemented. Within this framework, partners will have to (1) make their decision frame explicit to limit the freedom of decision-making, (2) to make up solutions only based on their decisional capability and (3) build a common decision space that includes solutions that respect their own interests and the interest of the partnership. Such a way to address this problem is linked to the decisional interoperability approach as defined in Daclin, Chen, and Vallespir (2006).

It is notable that, if partners use dedicated applications to manage, share and exploit their data, the use of technical solutions based on service-oriented architecture (SOA) (Srinivasan and Treadwell 2005; DiMare and Ma 2009; Raymond 2011) and ESB (ESB) (Chappell 2004) can be envisaged to ensure efficient interactions regarding data and applications.

\subsubsection{Implementation and tests}

According to the identified problems of interoperability and the selected solutions to solve them, a new order process between Telco and a dealer can be developed and implemented (Figure 11). It is notable that the selection of a given solution depends on different factors

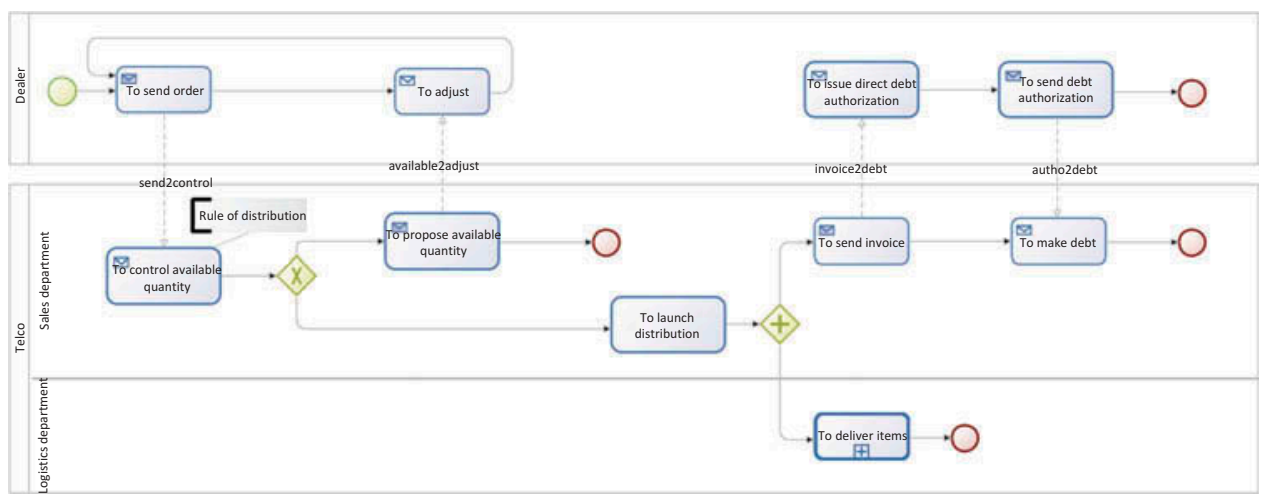

Figure 11. New process after implementation of interoperability solution. 
such as, for instance, tools used by partners, costs of interoperation defined at the first step, duration of the partnership, confidentiality (e.g. SOA requires to consider, with attention, this aspect because of the accessibility of services of IT system of a company), arduousness of the implementation of the solution (e.g. regarding the duration).

To implement this new process, a structured approach must be followed as proposed in the methodology. First of all, both companies must get the personnel concerned together to present the new process and plan the actions to carry out. The implementation will be done according to a project planning through a series of meetings between different people concerned (Synthesis group, Specialist group and Interviewees group) to collect needed data and to check and validate intermediate results. The various responsibilities are to be assigned to different people as who are in charge of implementing the process, maintaining process in operational phase, updating data whenever necessary and coordinating in case of exception handing and so on. A set of decisions to take (either periodically or upon events) for the governance of this new interoperability process must be identified as well as the associated decision-makers. During and after implementation, tests are to be performed. This consists of verifying that the internal processes of the two companies can effectively work together to exchange information as required. If the test results conform to functional requirements, then the performance evaluation (cost, time and quality) will be done.

The costs of the implementation of this new process (new activities for dealer and Telco, tool to map data) have to respect those expressed at the first step of the methodology. For instance, regarding the solution implemented to solve the data incompatibility, the costs of transformation and mapping are assumed by each partner, that is partners ensure that received information will be transformed into its own format and correctly translated. In more complex cases, depending on the duration (long-term, middle-term or short-term) of the partnership, the frequency of partnerships for a given partner, the partner where a deficiency occurs, the tools used to exchange and exploit (mail, IT system, manual etc.) data (or product, material etc.), some negotiations can be required to decide which cost is entirely or partially assumed by partners.

Right after the implementation of solutions, the performance of interoperation is evaluated. The result of this evaluation is compared with the objectives defined at the beginning of the application (phase of definition of objectives and needs).

As far as the cost of interoperation is concerned, no deficiencies are detected. On the one hand, partners respect the cost assigned to the exchange of information $\left(C_{\mathrm{ex}}\right)$. On the other hand, the cost assigned to the use of information exchanged $\left(C_{\mathrm{op}}\right)$ conform to the objective. For instance, the cost locked-up by Telco to exploit orders sent by the dealer is respected.

Regarding the duration of interoperation, a deficiency is detected on the duration of exchange $\left(T_{\text {ex }}\right)$. This deficiency concerns the exchange of the direct debt authorisation. This deficiency is detected thanks to the evaluation of the duration between the date at which information is sent and the date at which information is received (for each exchange). It is notable that this deficiency does not impact the cost of exchange. Indeed, when interoperation has been tested, a server maintenance operation was planned and has been triggered during the task 'To send debt authorisation' leading to speed reduction of the flow.

Finally, for the quality of interoperation, no deficiencies are detected. For instance, for all information sent by Telco to its dealer: 
Table 14. Performance of interoperation between Telco and a dealer and detail of the deficiency on duration of interoperation.

\begin{tabular}{|c|c|c|c|c|c|c|c|}
\hline \multicolumn{2}{|c|}{$\begin{array}{l}\text { Cost of interoperation } \\
\qquad\left(C_{i n}\right)\end{array}$} & \multicolumn{2}{|c|}{$\begin{array}{l}\text { Time of interoperation } \\
\qquad\left(T_{i n}\right)\end{array}$} & \multicolumn{3}{|c|}{ Quality of interoperation $\left(Q_{i n}\right)$} & \multirow[b]{2}{*}{$\begin{array}{l}\text { Performance of } \\
\text { interoperation } \\
\qquad\left(P_{\text {in }}\right)\end{array}$} \\
\hline $\begin{array}{l}\text { Cost of } \\
\text { exchange } \\
\left(C_{\mathrm{ex}}\right)\end{array}$ & $\begin{array}{c}\text { Cost of } \\
\text { operation } \\
\left(C_{\mathrm{op}}\right)\end{array}$ & $\begin{array}{l}\text { Time to } \\
\text { exchange } \\
\quad\left(T_{\text {ex }}\right)\end{array}$ & $\begin{array}{l}\text { Time of } \\
\text { operation } \\
\left(T_{\mathrm{op}}\right)\end{array}$ & $\begin{array}{l}\text { Quality of } \\
\text { exchange } \\
\quad\left(Q_{\mathrm{ex}}\right)\end{array}$ & $\begin{array}{l}\text { Quality of } \\
\text { operation } \\
\left(Q_{\mathrm{op}}\right)\end{array}$ & $\begin{array}{l}\text { Conformity } \\
\qquad\left(Q_{\mathrm{c}}\right)\end{array}$ & \\
\hline \multirow[t]{2}{*}{0} & 0 & 1 & 0 & 0 & 0 & 0 & 1 \\
\hline & & & & \multicolumn{4}{|c|}{$\mathrm{T}_{\text {int }}$} \\
\hline \multicolumn{4}{|l|}{ Location } & Expected $T_{\mathrm{ex}}$ & Expected $T_{\mathrm{op}}$ & Effective $T_{\mathrm{ex}}$ & x Effective $T_{\text {op }}$ \\
\hline \multirow{5}{*}{\multicolumn{4}{|c|}{$\begin{array}{l}\text { To send order } \rightarrow \text { To control available quantity } \\
\text { To propose available quantity } \rightarrow \text { To adjust } \\
\text { To send invoice } \rightarrow \text { To issue direct debt authorisation } \\
\text { To send debt authorisation } \rightarrow \text { To make debt }\end{array}$}} & $2 \min$ & $1 \mathrm{~min}$ & $2 \min$ & $1 \mathrm{~min}$ \\
\hline & & & & $2 \min$ & $1 \mathrm{~min}$ & $2 \min$ & $1 \mathrm{~min}$ \\
\hline & & & & $3 \mathrm{~min}$ & $1 \mathrm{~min}$ & $3 \mathrm{~min}$ & $1 \mathrm{~min}$ \\
\hline & & & & $4 \min$ & $1 \mathrm{~min}$ & $10 \min$ & $1 \mathrm{~min}$ \\
\hline & & & & $15 \mathrm{~min}$ & & $21 \mathrm{~min}$ & \\
\hline
\end{tabular}

- All the information is effectively received by the dealer (quality of exchange)

- The number of pieces of information received by the dealer is equal to the number sent (quality of operation)

- The information received by dealer conforms fully to the requested information (quality of conformity).

The overall result of the performance of interoperation is given by Table 14. Since a gap is detected on a duration of exchange, leading to total duration of interoperation greater than the objective expressed at the step 'Definition of objectives and needs' (for the record, duration of interoperation do not have to exceed one quarter of the duration to perform a complete order process), the coefficient 1 is allocated to this criteria.

Finally, a new measure of compatibility is performed to (1) verify that all selected solutions have removed all incompatibilities and (2) highlight incompatibilities not detected through the phase of 'analysis of the existing systems'. This new measure (Table 15) shows that most of identified incompatibilities are removed. However, one incompatibility remains. This one has not been detected through the analysis of the existing systems and is located at the organisational level for the data view. Indeed, neither responsibilities nor authorities are explicitly defined. For instance, it can lead to a loss of time, during the execution of the process, because of an exchange of data with a person who is not authorised or not concerned by the activity of the exchange.

Table 15 . Compatibility matrix after the implementation of interoperability solutions.

\begin{tabular}{lccccccc}
\hline & \multicolumn{2}{c}{ Conceptual } & & \multicolumn{2}{c}{ Organisational } & & \multicolumn{2}{c}{ Technology } \\
\cline { 2 - 3 } \cline { 6 - 7 } & Syntactic & Semantic & & $\begin{array}{c}\text { Authorities } \\
\text { responsibilities }\end{array}$ & Organisation & $\begin{array}{c}\text { Platform } \\
\text { application }\end{array}$ & Communication \\
\hline Business & 0 & 0 & 0 & 0 & 0 & 0 \\
Process & 0 & 0 & 0 & 0 & 0 & 0 \\
Services & 0 & 0 & 0 & 0 & 0 & 0 \\
Data & 0 & 0 & $\mathbf{1}$ & 0 & 0 & 0 \\
\hline
\end{tabular}


In this case, partners have to process a new analysis of the existing systems at the organisational level to refine this kind of incompatibility and select a better solution to remove it.

\section{Conclusion and prospects}

This article has presented a methodology for developing enterprise interoperability. It can be used in a company to either establish an interoperation which does not exist yet or to improve existing interoperability. Based on existing works performed on interoperability, an enterprise interoperability framework is defined and it allows to structure and select solutions with regard to the dimensions of views, abstraction levels and approaches. Two kinds of measures to evaluate interoperability are developed and are applicable before any partnership and during the partnership. Finally, a structured approach is built to guide users in the selection and the implementation of interoperability approach. It is important to note that the success of the application of the methodology requires, beforehand, the identification and structuring of a set of interoperability solutions according to the three dimensions of the interoperability framework, that is a solution that solves a problem of interoperability for a given interoperability view and abstraction level and that satisfies an interoperability approach.

This methodology is mainly supported by the framework of interoperability. As a consequence, works to develop are mainly related to the measure of interoperability. Regarding the potentiality, this approach allows a given enterprise to evaluate its ability to interoperate with other potential partners. However, it does not consider solutions and recommendation to evolve through potentiality levels and to improve it. In this way, it is necessary to develop these two aspects to guide enterprise in their evolution.

Regarding the interoperability degree, it includes only the measure of compatibility and performances. Other attributes to measure interoperability can be considered. For instance, the security aspect to exchange information between partners could be integrated. Furthermore, it will be interesting to integrate these performance measurements to the global performances of a partnership. It means measuring the impact on business, to verify and to justify (or not) the necessity to implement interoperability.

Finally, another perspective is to refine the scaling of values in the compatibility and performance matrix. Indeed, boolean values ( 0 or 1$)$ do not allow accurate evaluation of (1) the compatibility level and (2) the achievement level in term of performance. Regarding compatibility measurement, this means that partners are compatible or not. As far as performance measurement is concerned, this means that partners are efficient or not. Thus, it would be interesting to develop intermediate values (e.g. 0.25, 0.5, 0.75) allowing partners to know precisely their degree of compatibility and performance. It will allow, for instance, to give priority to a given solution or performance rather than other ones and according to the results of evaluation.

\section{Notes}

1. Enterprise applications are the set of processes, resources and information shared and exchanged among these resources (machine, human, computer) (ISO 2003).

2. According to the frameworks presented previously:

- Conceptual interoperability aims to ensure that information exchanged shares the same meaning and syntax to enable systems to process information exchanged. This requires definition of a common semantic on the basis of structured language (e.g. xml, xmi). 
- Organisational interoperability is related to the organisation of business processes and internal structure to improve exchange of information. This requires modelling of business processes and ensuring their availability.

- Technical interoperability is concerned by computer systems to collect, store, process, exchange and distribute information.

\section{References}

ATHENA. 2003. "ATHENA Integrated Project IS 507849." Advanced Technologies for Interoperability of Heterogeneous Enterprise Networks and their Applications, FP6-2002-IST1, Integrated Project Proposal.

ATHENA. 2005a. Framework for the Establishment and Management Methodology, ATHENA Integrated Project, Deliverable DA1.4.

ATHENA. 2005b. Report on Methodology Description and Guidelines Definition, ATHENA Integrated Project, deliverable A1.3.1.

ATHENA. 2006. Semantic Annotation Language and Tool for Information and Business Processes, ATHENA Integrated Project, Deliverable A 3.3.

Bachman, J. 2005. "A New Service-Oriented Architecture Maturity Model." Accessed June 16, 2014. http://soa.omg.org/Uploaded\%20Docs/SOA/SOA_Maturity.pdf

Bana e Costa, C., and M. Chagas. 2004. "A Career Choice Problem: An Example of How to Use MACBETH to Build a Quantitative Value Model Based on Qualitative Value Judgements." European Journal of Operational Research 153: 323-331.

Bourey, J.-P., R. Grangel, G. Doumeingts, and A. J. Berre. 2007. Report on Model Driven Interoperability, INTEROP Network Of Excellence IS 508011, Deliverable DTG 2.3.

C4ISR Architecture Working Group (AWG). 1998. Levels of Information Systems Interoperability (LISI), US Department of Defense.

Campos, C., I. Mart, R. Grangel, A. Mascherpa, and R. Chalmeta. 2008. "A Methodological Proposal for the Development of an Interoperability Framework." Proceedings of MDISIS International Conference, Montpellier, June 16.

Camposa, C., R. Chalmeta, R. Grangel, and R. Poler. 2013. "Maturity Model for Interoperability Potential Measurement." Journal of Information Systems Management 30 (3): 218-234.

Chappell, D. 2004. Enterprise Service Bus: Theory in Practice, 352. New York: O'Reilly Media.

Charalabidis, Y., R. Jardim-Gonçalves, and K. Popplewell, eds. 2010. Developing a Science Base for Enterprise Interoperability. London: Springer.

Chen, D., and N. Daclin. 2006. "Framework for Enterprise Interoperability." In 2nd IFAC Workshop on Enterprise Integration, Interoperability and Networking, EI2N, Bordeaux, March 22-24.

Chen, D., and G. Doumeingts. 1996. "The GRAI-GIM Reference Model, Architecture and Methodology." Chap. 7. In Architectures for Enterprise Integration, edited by P. Bernus, L. Nemes, and T. Williams, 102-126. London: Chapman \& Hall.

Chen, D., and F. Vernadat. 2004. "Standards on Enterprise Integration and Engineering-State of the Art." International Journal of Computer Integrated Manufacturing (IJCIM) 17 (3): 235-253.

CMM. 2004. Carnegie Mellon Software Engineering Institute: SEI Software Engineering Process Management Program.

COIN. 2011. Enterprise Collaboration and Interoperability. European FP7 Integrated Project. Accessed June 16, 2014. http://www.coin-ip.eu/

Daclin, N., D. Chen, and B. Vallespir. 2006. "Decisional Interoperability: Concepts and Formalization." 7th IFIP Working Conference on Virtual Enterprises (PRO-VE'06), Helsinki, September.

Daclin, N., D. Chen, and B. Vallespir. 2008a. Enterprise Interoperability Measurement: The Potentiality. INCOSE INSIGHT, Special feature - The Best of France - Forum académique et robAFIS, 11-3.

Daclin, N., D. Chen, and B. Vallespir. 2008b. "Methodology for Enterprise Interoperability." 17th IFAC World Congress, Seoul, July.

Department of Defense. 2001. Department of Defense Dictionary of Military and Associated Terms, US Department of Defense. 
Desai, J. 2010. Service Level Agreements - A Legal and Practical Guide, 120. Ely: IT Governance Publishing.

Dimare, J., and R. S. Ma. 2009. Service-Oriented Architecture - Revolutionizing Today's Banking Systems. Somers, NY: IBM Global Business Services.

Doumeingts, G., B. Vallespir, and D. Chen. 1998. "GRAI Grid Decisional Modelling." In Handbook on Architectures of Information Systems, edited by P. Bernus, K. Mertins, and G. Schmidt. Heidelberg: Springer.

Ducq, Y., D. Chen, and G. Doumeingts. 2012. "A Contribution of System Theory to Sustainable Enterprise Interoperability Science Base." Computers in Industry 63 (8): 844-857.

ENSEMBLE. 2010. A Coordination and Support Action to Develop Enterprise Interoperability Science Base. Accessed June 16, 2014. http://cordis.europa.eu/fp7/ict/enet/documents/abstractprojects/abstract-ensemble.pdf

ESPRIT Consortium AMICE. 1993. CIMOSA: Open Architecture for CIM. AMICE Consortium, Second and revised version. Berlin: Springer Verlag.

European Commission. 2008. European Interoperability Framework for European Public Services $(E I F)$. Version 2.0 draft document as basis for EIF 2.0.

Fewell, S., and T. Clark. 2003. "Organisational Interoperability: Evaluation and Further Development of the OIM Model." 8th International Command and Control Research and Technology Symposium, Washington DC, June. 17-19.

Ford, C. T. 2008. "Interoperability Measurement." PhD thesis, Department of the Air Force Air University, Air Force Institute of Technology.

Gonzalez-Baixauli, B., J. C. S. Do Prado Leite, and J. Mylopoulos. 2004. "Visual Variability Analysis for Goal Models." 12th IEEE International Conference on Requirements Engineering (RE), Kyoto, September 6-10, 198-207.

Guédria, W., Y. Naudet, and D. Chen. 2013. "Maturity Model for Enterprise Interoperability." Enterprise Information Systems: 28 p. doi:10.1080/17517575.2013.805246.

Guo, F. B., M. Z. Wang, and J. J. Liao. 2011. "A Measurement Method of the Interoperability of Integrated Systems Based on Process Net." Applied Mechanics and Materials 88-89: 99-103.

Hamilton, J., J. D. Rosen, and P. A. Summers. 2002. "An Interoperability Road Map for C4ISR Legacy Systems." Acquisition Review Journal Winter: 16.

IDEAS. 2003. "IDEAS Project Deliverables (WP1-WP7)." Interoperability Development for Enterprise Application and Software, IST - 2001 - 37368, Public reports.

IEEE. 1990. IEEE Standard Computer Dictionary: A Compilation of IEEE Standard Computer Glossaries. New York: Institute of Electrical and Electronics Engineers.

IFEAD. 2004. Extended Enterprise Architecture Maturity Model (E2AMM). Institute for Enterprise Architecture Developments, Support Guide Version 2.0.

INTEROP. 2006a. "INTEROP Network Of Excellence IS 508011." Enterprise InteroperabilityFramework and Knowledge Corpus-Advanced Report. INTEROP Deliverable DI.2, DI (Domain Interoperability).

INTEROP. 2006b. Enterprise Modelling and Ontologies for Interoperability. INTEROP Deliverable D8.2.

ISO. 1999. ISO 14258 - Industrial Automation Systems - Concepts and Rules for Enterprise Models. Geneva: International Organization for Standardization. ISO TC184/SC5/WG1.

ISO. 2002a. ISO 16100, 1 -Industrial Automation Systems and Integration-Manufacturing Software Capability Profiling for Interoperability - Part 1: Framework. Geneva: International Organization for Standardization. ISO/TC 184/SC 5/WG 4, 2002.

ISO. 2002b. Enterprise Integration - Framework for Enterprise Modelling. Geneva: International Organization for Standardization. ISO/CEN 19439 CEN TC310/WG1 and ISO TC184 SC5/WG1.

ISO. 2003. ISO 15745 - 1, Industrial Automation Systems and Integration - Open Systems Application Integration Framework - Part 1: Generic Reference Description. Geneva: International Organization for Standardization. ISO TC184/SC5, 2003.

ISO. 2011. Advanced Automation Technologies and Their Applications - Part 1: Framework for Enterprise Interoperability. Geneva: International Organization for Standardization. ISO 11354, ISO/TC $184 / \mathrm{SC} 5$.

Jardim-Goncalves, R., A. Grilo, C. Agostinho, F. Lampathaki, and Y. Charalabidis. 2013. "Systematisation of Interoperability Body of Knowledge: The Foundation for Enterprise Interoperability as a Science." Enterprise Information Systems 7 (1): 7-32. 
Kasunic, M., and W. Anderson. 2004. "Measuring Systems Interoperability: Challenges and Opportunities." Software Engineering Measurement and Analysis Initiative, Technical Note CMU/SEI - $2004-\mathrm{TN}-003$.

Krafzig, D., K. Banke, and D. Slama. 2005. Enterprise SOA: Service-Oriented Architecture Best Practices, 382. Upper Saddle River, NJ: Prentice Hall Professional.

Mallek, S., N. Daclin, and V. Chapurlat. 2012. "The Application of Interoperability Requirement Specification and Verification to Collaborative Processes in Industry." Computers in Industry 63 (7): 643-658.

Marca, D. A., and C. L. Mcgowan. 2005. IDEF0 and SADT: A Modeler's Guide. Auburndale, MA: OpenProcess.

Menzel, C. P., and R. J. Mayer. 1998. "The IDEF Family of Languages." In Handbook on Architectures of Information Systems, edited by P. Bernus, K. Mertins, and G. Schmidt. Berlin: Springer.

Morris, E., L. Levine, C. Meyers, P. Place, and D. Plakosh. 2004. System of Systems Interoperability (SOSI): Final Report, Technical report CMU/SEI - 2004 - TR - 004.

NASCIO. 2003. NASCIO Enterprise Architecture Maturity Model. National Association of State Chief Information Officers. Version 1.3.

Naudet, Y., T. Latour, W. Guedria, and D. Chen. 2010. "Towards a Systemic Formalisation of Interoperability." Computers in Industry 61: 176-185.

NEHTA. 2007. "Towards a Health Interop Framework." Version 1.0. www.nehta.gov.au

OASIS. 2006. "OASIS Business Centric Methodology." Specification Version 1.0. Accessed June 16, 2014. http://www.oasis-open.org/

OMG. 2003. "MDA Guide Version 1.0.1." Object Management Group, omg/2003-06-01. Accessed June 16, 2014. http://www.omg.org/

OMG. 2011. "Business Process Model and Notation (BPMN)." Version 2.0. Accessed June 16, 2014. http://www.bpmn.org/

Oxford English Dictionary. 1999. Oxford: Oxford University Press.

Panetto, H., and J. Cecil. 2013. "Information Systems for Enterprise Integration, Interoperability and Networking: Theory and Applications." Enterprise Information Systems 7 (1): 1-6.

Raymond, G. 2011. SOA: Architecture logique - Principes, structures et bonnes pratiques, Livre blanc, Version 2.1, Softeam.

Ross, D. 1977. "Structured Analysis (SA): A Language for Communicating Ideas." IEEE Transactions on Software Engineering se-3 (1): 16-34.

Singular Enterprise. 2003. Implementation Methodology - Blue Print - Demo TelCo.

Srinivasan, L., and J. Treadwell. 2005. An Overview of Service-Oriented Architecture, Web Services and Grid Computing, vol. 2. Palo Alto, CA: HP Software Global Business Unit.

Tardieu, H., A. Rochfeld, and R. Colletti. 2000. La Méthode MERISE - Principes Et Outils. Paris Cedex: Edition d'Organisation. Editions 2000 [in French].

Tolk, A., S. Y. Diallo, and C. D. Turnitsa. 2007. "Applying the Levels of Conceptual Interoperability Model in Support of Integratability, Interoperability, and Composability for System-Of-Systemsengineering." Systemics Cybernetics and Informatics 5 (5): 65-74.

Valipour, M. H., B. Amirzafari, K. Niki Maleki, and N. Daneshpour. 2009. "A Brief Survey of Software Architecture Concepts and Service Oriented Architecture." In Proceedings of 2nd IEEE International Conference on Computer Science and Information Technology, ICCSIT'09, 34-38, China.

Van Staden, S., and J. Mbale. 2012. "The Information Systems Interoperability Maturity Model (ISIMM): Towards Standardizing Technical Interoperability and Assessment within Government." International Journal of Information Engineering and Electronic Business 4: $36-41$.

Verma, D. 1999. Supporting Service Level Agreements on IP Networks. Indianapolis, IN: Macmillan Technology Series, Sams.

Vernadat, F. B. 1996. Enterprise Integration Modeling and Integration: Principles and Applications. London: Chapman \& Hall.

Wang, X., and X. W. Xu. 2012. "DIMP: An Interoperable Solution for Software Integration and Product Data Exchange.” Enterprise Information Systems 6 (3): 291-314. 
Yahia, E., A. Aubry, and H. Panetto. 2012. "Formal Measures for Semantic Interoperability Assessment in Cooperative Enterprise Information Systems." Computers in Industry 63 (5): 443-457. doi:10.1016/j.compind.2012.01.010.

Zachman, J. 2003. The Zachman Framework for Enterprise Architecture: Primer for Enterprise Engineering and Manufacturing. La Cañada, CA: Zachman International.

Zadeh, L. A. 1978. "Fuzzy Sets as a Basis for a Theory of Possibility." Fuzzy Sets and Systems 1: 3-28. 